\title{
Validation of Plasmodium falciparum deoxyhypusine synthase as an antimalarial target
}

\author{
Aiyada Aroonsri ${ }^{1}$, Navaporn Posayapisit ${ }^{1}$, Jindaporn Kongsee ${ }^{2}$, Onsiri Siripan ${ }^{1,3}$, Danoo Vitsupakorn ${ }^{1}$,

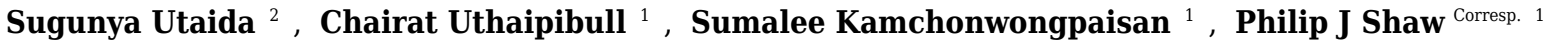 \\ ${ }^{1}$ Protein-Ligand Engineering and Molecular Biology Laboratory, Medical Molecular Biology Research Unit, National Center for Genetic Engineering and \\ Biotechnology (BIOTEC), National Science and Technology Development Agency (NSTDA), Pathum Thani, Thailand \\ 3 Fisheries Industrial Technology Research and Development Division, Department of Fisheries, Bangkok, Thailand \\ Corresponding Author: Philip J Shaw \\ Email address: philip@biotec.or.th
}

Background. Hypusination is an essential post-translational modification in eukaryotes. The two enzymes required for this modification, namely deoxyhypusine synthase (DHS) and deoxyhypusine hydrolase are also conserved. Plasmodium falciparum human malaria parasites possess genes for both hypusination enzymes, which are hypothesized to be targets of antimalarial drugs.

Methods. Transgenic $P$. falciparum parasites with modification of the PF3D7_1412600 gene encoding PfDHS enzyme were created by insertion of the $\mathrm{g} / \mathrm{mS}$ riboswitch or the M9 inactive variant. The PfDHS protein was studied in transgenic parasites by confocal microscopy and Western immunoblotting. The biochemical function of PfDHS enzyme in parasites was assessed by hypusination and nascent protein synthesis assays. Gene essentiality was assessed by competitive growth assays and chemogenomic profiling.

Results. Clonal transgenic parasites with integration of $\mathrm{glmS}$ riboswitch downstream of the PfDHS gene were established. PfDHS protein was present in the cytoplasm of transgenic parasites in asexual stages. The PfDHS protein could be attenuated five-fold in transgenic parasites with an active riboswitch, whereas PfDHS protein expression was unaffected in control transgenic parasites with insertion of the riboswitch-inactive sequence. Attenuation of PfDHS expression for $72 \mathrm{~h}$ led to a significant reduction of hypusinated protein; however, global protein synthesis was unaffected. Parasites with attenuated PfDHS expression showed a significant growth defect, although their decline was not as rapid as parasites with attenuated dihydrofolate reductase-thymidylate synthase (PfDHFR-TS) expression. PfDHS-attenuated parasites showed increased sensitivity to $N^{1}$-guanyl-1,7-diaminoheptane, a structural analog of spermidine, and a known inhibitor of DHS enzymes.

Discussion. Loss of PfDHS function leads to reduced hypusination, which may be important for synthesis of some essential proteins. The growth defect in parasites with attenuated Pf DHS expression suggests that this gene is essential. However, the slower decline of PfDHS mutants compared with PfDHFR-TS mutants in competitive growth assays suggests that PfDHS is less vulnerable as an antimalarial target. Nevertheless, the data validate PfDHS as an antimalarial target which can be inhibited by spermidine-like compounds. 


\section{Validation of Plasmodium falciparum deoxyhypusine 2 synthase as an antimalarial target}

3

4 Aiyada Aroonsri ${ }^{1}$, Navaporn Posayapisit ${ }^{1}$, Jindaporn Kongsee ${ }^{2}$, Onsiri Siripan ${ }^{1,3}$, Danoo

5 Vitsupakorn $^{1}$, Sugunya Utaida ${ }^{2}$, Chairat Uthaipibull ${ }^{1}$, Sumalee Kamchonwongpaisan ${ }^{1}$ and Philip

6 J. Shaw ${ }^{1}$

7 1Protein-Ligand Engineering and Molecular Biology Laboratory, Medical Molecular Biology

8 Research Unit, National Center for Genetic Engineering and Biotechnology (BIOTEC), National

9 Science and Technology Development Agency (NSTDA), Pathum Thani, Thailand

10 2Department of Biotechnology, Faculty of Science and Technology, Thammasat University, 11 Khlong Luang, Pathum Thani, Thailand.

$12{ }^{3}$ Current address: Fisheries Industrial Technology Research and Development Division, 13 Department of Fisheries, Kaset-Klang, Chatuchak, Bangkok, Thailand.

Corresponding Author:

Philip J. Shaw

National Center for Genetic Engineering and Biotechnology (BIOTEC), National Science and Technology Development Agency (NSTDA), 113 Thailand Science Park, Khlong Nueng, Khlong Luang, Pathum Thani 12120, Thailand

Email address: philip@,biotec.or.th

\section{Abstract}

\section{Background.}

Hypusination is an essential post-translational modification in eukaryotes. The two enzymes required for this modification, namely deoxyhypusine synthase (DHS) and deoxyhypusine hydrolase are also conserved. Plasmodium falciparum human malaria parasites possess genes for both hypusination enzymes, which are hypothesized to be targets of antimalarial drugs.

Methods. 
31 Transgenic $P$. falciparum parasites with modification of the PF3D7_1412600 gene encoding

32 PfDHS enzyme were created by insertion of the $g \operatorname{lm} S$ riboswitch or the M9 inactive variant. The

33

34

$P f$ DHS protein was studied in transgenic parasites by confocal microscopy and Western immunoblotting. The biochemical function of PfDHS enzyme in parasites was assessed by hypusination and nascent protein synthesis assays. Gene essentiality was assessed by competitive growth assays and chemogenomic profiling.

\section{Results.}

Clonal transgenic parasites with integration of $g \operatorname{lm} S$ riboswitch downstream of the PfDHS gene were established. PfDHS protein was present in the cytoplasm of transgenic parasites in asexual stages. The PfDHS protein could be attenuated five-fold in transgenic parasites with an active riboswitch, whereas $P f$ DHS protein expression was unaffected in control transgenic parasites with insertion of the riboswitch-inactive sequence. Attenuation of PfDHS expression for $72 \mathrm{~h}$ led to a significant reduction of hypusinated protein; however, global protein synthesis was unaffected. Parasites with attenuated PfDHS expression showed a significant growth defect, although their decline was not as rapid as parasites with attenuated dihydrofolate reductasethymidylate synthase ( $P f$ DHFR-TS) expression. PfDHS-attenuated parasites showed increased sensitivity to $N^{1}$-guanyl-1,7-diaminoheptane, a structural analog of spermidine, and a known inhibitor of DHS enzymes.

\section{Discussion.}

Loss of PfDHS function leads to reduced hypusination, which may be important for synthesis of some essential proteins. The growth defect in parasites with attenuated $\underline{P f}$ DHS expression suggests that this gene is essential. However, the slower decline of PfDHS mutants compared with $P f$ DHFR-TS mutants in competitive growth assays suggests that $P f \mathrm{DHS}$ is less vulnerable as an antimalarial target. Nevertheless, the data validate PfDHS as an antimalarial target which can be inhibited by spermidine-like compounds.

\section{Introduction}

The incidence of malaria has declined around the world in recent years, with a $21 \%$ reduction reported worldwide during the period 2010-2015 (World Health Organization, 2016). Programs to eliminate the disease in endemic countries could be thwarted by evolving Plasmodium falciparum parasite resistance to artemisinin-combination therapies that are widely 
62

63

64

65

66

67

68

69

70

used to treat and prevent infections (Woodrow \& White, 2016). New drugs with novel modes of action are needed to combat drug-resistant parasites. Identification of novel drug targets should accelerate the development of such antimalarials.

Polyamines are nitrogenous base compounds that are essential for cellular proliferation and development. Malaria parasites synthesize large amounts of polyamines, in which spermidine is a major metabolite present in all stages of development (Teng et al., 2009). Moreover, several different polyamine analogues possess antimalarial activity, suggesting that polyamine metabolism constitutes novel drug targets (reviewed in [Clark et al., 2010]). One of the main uses of spermidine in eukaryotes is for hypusination of translation initiation factor $5 \mathrm{~A}$ (eIF5A) protein; two enzymes are required for this post-translational modification, namely deoxyhypusine synthase (DHS) and deoxyhypusine hydrolase (reviewed in [Park et al., 2010]). $P$. falciparum possesses a single gene encoding eIF5A, and functional studies of the parasite eIF5A protein have shown that it is a substrate for hypusination (Molitor et al., 2004). Malaria parasites also possess canonical enzymes for hypusination of eIF5A, and the $P$. falciparum DHS enzyme (PfDHS) uses eIF5A protein as a substrate for incorporation of spermidine (Kaiser et al., 2007). The enzymatic activity of PfDHS is inhibited by $N^{1}$-guanyl-1,7-diaminoheptane (GC7), a known inhibitor of human DHS enzyme (Kaiser et al., 2007). Hypusination of eIF5A by PfDHS is likely to be essential since P. falciparum is moderately sensitive to growth inhibition by GC7 (Kaiser et al., 2001) and no insertions of piggyBac transposon within the PfDHS gene are tolerated (Zhang et al., 2018). The orthologous gene encoding DHS enzyme in the murine malaria parasite $P$. berghei is essential, since clonal transgenic $P$. berghei parasites with knockout of the DHS gene cannot be isolated (Kersting et al., 2016), and P. berghei DHS knockout parasites have a severe growth defect causing them to rapidly disappear from host animals co-infected with other transgenic parasites (Bushell et al., 2017). glmS riboswitch tool (Prommana et al., 2013) was used to attenuate PfDHS expression. Attenuation of PfDHS expression led to defects in hypusination of eIF5A and growth of transgenic parasites. Moreover, attenuation of PfDHS expression specifically sensitized parasites to GC7, a known inhibitor of PfDHS enzyme activity. 
93

94

95

96

97

98

101

102

103

104

105

106

107

108

109

110

111

112

113

114

115

116

117

118

119

120

121

122

123

\section{Materials and Methods}

\section{Ethics statement}

Human erythrocytes were obtained from donors after providing informed written consent, following a protocol approved by the Ethics Committee, National Science and Technology Development Agency, Pathum Thani, Thailand, document no. 0021/2560.

\section{Construction of DNA transfection vectors}

$1493 \mathrm{bp}$ of homologous targeting sequence from the PF3D7_1412600 gene encoding deoxyhypusine synthase (PfDHS) was PCR-amplified from $P$. falciparum strain 3D7 genomic DNA using primers pGFP_glmS_DHSF and GFP_glmS_DHSR (Table S1) and Phusion® DNA polymerase (Thermo Fisher Scientific, USA) following the manufacturer's recommendations. The pGFP_glmS and pGFP_M9 plasmids carrying $g \operatorname{lm} S$ riboswitch element and the M9 inactive variant, respectively (Prommana et al., 2013) were first modified to remove unnecessary hsp86 promoter and REP20 sequences by digestion with AflII and BgIII. The digested plasmids were religated to create Sim_pGFP_glmS and Sim_pGFP_M9 vectors. The PfDHS targeting sequence was cloned into NheI and KpnI (New England Biolabs [NEB], USA) digested vectors using a Gibson assembly kit (NEB). 960 bp of homologous targeting sequence from the PF3D7_1364900 gene encoding ferrochelatase (PfFC) was PCR-amplified from P. falciparum strain 3D7 genomic DNA using primers PfFCSacIIF and PfFCKpnIR (Table S1) and GoTaq® DNA polymerase (Promega Corporation, USA) following the manufacturer's recommendations. The PfFC targeting sequence DNA was digested with SacII and KpnI restriction enzymes (NEB) and cloned into pGFP_glmS plasmid (Prommana et al., 2013) digested with the same enzymes.

\section{Plasmodium falciparum culture and DNA transfection}

P. falciparum strain 3D7 (reference strain) and transgenic parasite derivatives were cultured in vitro following the standard method (Trager \& Jensen, 1976), with the modification 
124 of $0.5 \%$ Albumax I (Gibco ${ }^{\mathrm{TM}}$, Thermo Fisher Scientific, USA ) replacing human serum

125 (Cranmer et al., 1997). Human O+ erythrocytes were obtained from donors after obtaining their

126 written informed consent. 2\% hematocrit was used for most parasite cultures, with slightly

127 higher hematocrit (up to 4\%) used during blasticidin selection steps of DNA transfection.

128 Parasites were synchronized to ring stages by sorbitol treatment (Lambros \& Vanderberg, 1979).

129 Approximately $50 \mu \mathrm{g}$ of plasmid DNA was used for each parasite transfection experiment.

130 Transfection was performed by the method of direct transfection of infected host cells (Wu et al.,

131 1995) or invasion of DNA-loaded erythrocytes (Deitsch, Driskill \& Wellems, 2001). Transgenic

132 parasites were selected by treatment with $2 \mu \mathrm{g} / \mathrm{mL}$ blasticidinS-HCl (Gibco), which was added to

133 parasite culture 48 hours post-transfection. Parasites were cultured under drug selection until

134 resistant parasites emerged (three weeks), after which drug was removed and culture continued

135 for two weeks. The drug on-off cycle (two weeks each) was repeated to enrich for integrant

136 parasites in the population. Integrants were detected by PCR assay. Genomic DNA samples were

137 obtained for genotypic analysis of transgenic parasites using a Genomic DNA Mini Kit

138 (Blood/Cultured Cell) (Geneaid Biotech, Taiwan). Integration at the PfDHS locus was checked

139 using primers DHS_intF and 3UTRpbDT_glmSR (Table S1). PCRs contained 20 ng of genomic

140 DNA, $500 \mathrm{nM}$ of each primer, 1 unit of Phusion polymerase (Thermo Scientific ${ }^{\mathrm{TM}}$, Thermo

141 Fisher Scientific, USA) and $2.5 \mathrm{mM} \mathrm{MgCl}_{2}$. The reaction conditions were: $98^{\circ} \mathrm{C}$ for $3 \mathrm{~min}$

142 followed by 35 cycles of $98^{\circ} \mathrm{C} 10 \mathrm{sec}, 52^{\circ} \mathrm{C} 30 \mathrm{sec}$ and $72^{\circ} \mathrm{C}$ for $90 \mathrm{sec}$ and final extension at

$14372^{\circ} \mathrm{C}$ for $5 \mathrm{~min}$. The presence of transfected DNA in transfection experiments to modify the

144 PfFC gene was checked using primers BglIIPfFCF and 3UTRpbDTglmSR (Table S1). A control

145 PCR to amplify the PfFC coding region and thus verify template DNA quality was performed

146 using primers BglIIPfFCF and PfFCKpnIR (Table S1). PCR assays of the PfFC locus contained

$14720 \mathrm{ng}$ of genomic DNA, $100 \mathrm{nM}$ of each primer, 1 unit of GoTaq polymerase (Promega) and 2.5

$148 \mathrm{mM} \mathrm{MgCl}_{2}$. The reaction conditions were: $95^{\circ} \mathrm{C}$ for $2 \mathrm{~min}$ followed by 30 cycles of $95^{\circ} \mathrm{C} 45 \mathrm{sec}$,

$14953^{\circ} \mathrm{C} 45 \mathrm{sec}$ and $62^{\circ} \mathrm{C}$ for $2 \mathrm{~min} 30 \mathrm{sec}$ and final extension at $62^{\circ} \mathrm{C}$ for $5 \mathrm{~min}$.

150

151

Clonal lines of integrant transgenic parasites were established by limiting dilution in 96-

152 well culture plates. A single clonal line from each transfection experiment, verified as integrant,

153 was randomly selected for further study. Clonal lines PfDHS_glmS (active riboswitch) and

154 PfDHS_M9 (inactive riboswitch) with integration at the PfDHS locus were obtained (Fig. S1). 
155 The clonal line PfFC_glmS (active riboswitch) with integration at the PfFC locus was obtained.

156 Plasmid integration in clonal transgenic lines was verified by Southern blot (Fig. S1 and S2). 20

$157 \mu \mathrm{g}$ samples of genomic DNA were digested overnight with restriction enzymes (NEB). BamHI

158 and AflII enzymes were used for the PfDHS locus and SpeI and HindIII enzymes were used for

159 the PfFC locus. Digested DNA samples were separated by electrophoresis and transferred by

160 capillary action to Hybond N+ nylon membrane (GE Healthcare, USA). Probes were synthesized

161 by PCR using primers pGFP_glmS_DHSF and GFP_glmS_DHSR for the PfDHS locus, and

162 PfFCSacIIF and PfFCKpnIR for the PfFC locus (Table S1) as described above. Probe labelling,

163 hybridization and detection were performed using a DIG High Prime DNA Labeling and

164 Detection Starter Kit II (Roche Diagnostics, Switzerland) following the manufacturer's

165 instructions. The integrant transgenic parasite line described in (Prommana et al., 2013), referred

166 to here as PfDHFR-TS_glmS, was used for growth studies. This parasite has a modified

167 PF3D7_0417200 gene encoding P. falciparum dihydrofolate reductase-thymidylate synthase

168 (PfDHFR-TS) with integration of GFP and $g \operatorname{lm} S$ riboswitch sequences.

169

170

171

172

173

174

175

176

177

178

179

180

181

182

183

184

185

\section{Confocal microscopy}

Specimens of transgenic parasites PfDHS_glmS, PfFC_glmS, PfDHFR-TS_glmS and 3D7 parental parasites were analyzed on a model FV 1000D IX81 confocal laser scanning microscope (Olympus, Japan). A 100X oil immersion objective lens (1.4 NA) was used. Parasite mitochondria were stained with $1 \mathrm{mM}$ Mitotracker (Invitrogen ${ }^{\mathrm{TM}}$, Thermo Fisher Scientific, USA) for $45-60 \mathrm{~min}$ at $37^{\circ} \mathrm{C}$. Parasite nuclei were stained with Hoechst 33342 (Invitrogen) diluted 1:1000 in RPMI medium (Gibco) for 5 min at $37^{\circ} \mathrm{C}$. GFP signal was detected with an Argon laser 488 nm (500 nm excitation/600 nm emission; laser power 15\%; high detector sensitivity $741 \mathrm{~V}$; gain $=1$ and offset $=12 \%$ ), Mitotracker signal was detected with a yellow diode laser $559 \mathrm{~nm}$ (575 nm excitation/675 nm emission; laser power 15\%; high detector sensitivity $641 \mathrm{~V}$; gain $=1$ and offset $=0 \%$, and Hoechst signal was detected with a UV laser diode $405 \mathrm{~nm}$ (425 nm excitation/475 nm emission; laser power 10\%; high detector sensitivity $615 \mathrm{~V}$; gain $=1$ and offset $=14 \%$ ). Images were obtained using a scan speed of $10.0 \mu \mathrm{s} /$ pixel and were analyzed using FV10-ASW 3.0 Viewer software (Olympus). 
186

187

188

189

190

191

192

193

194

195

196

197

198

199

200

201

202

203

204

205

206

207

208

209

210

211

212

213

214

215

\section{Western immunoblot of PfDHS-GFP protein}

$15 \mathrm{~mL}$ cultures of ring-stage PfDHS_glmS and PfDHS_M9 synchronized parasites at 5\% parasitemia and 3\% haematocrit were treated with $0,1.25,2.5$ and $5.0 \mathrm{mM} \mathrm{GlcN}$ for $24 \mathrm{~h}$ and harvested. Parasites were liberated from host cells by saponin lysis and washed with 1X PBS buffer (Thermo Scientific) containing 1X EDTA-free protease inhibitor cocktail (Sigma-Aldrich, Merck KGaA, Germany) and $0.7 \mu \mathrm{g} / \mathrm{mL}$ pepstatin (Sigma). Parasite proteins were extracted by freeze-thaw rupture. Protein lysate was diluted in NuPAGETM LDS sample buffer (4X, Thermo Scientific) and stored at $-80^{\circ} \mathrm{C}$. A $10 \mu \mathrm{g}$ sample from each protein lysate was separated in NuPAGE 4-12\% Bis-Tris Protein Gel (Invitrogen) with 1X NuPAGE MOPS SDS running buffer (Invitrogen). Proteins were transferred for $1.5 \mathrm{~h}$ at $30 \mathrm{~V}$ onto Immobilon-P PVDF membrane (Merck-Millipore, Merck KGaA, Germany) in 1X NuPAGE transfer buffer (Invitrogen) by using a XCell II Blot system (Invitrogen). Total protein was detected by Ponceau-S (Sigma) staining and an image of the stained membrane was captured on a flatbed scanner. After scanning, the Ponceau-S stain was removed from the membrane by washing with water. The destained membrane was incubated in blocking solution (5\% non-fat skimmed milk in 1XTBST buffer; $10 \mathrm{mM}$ Tris-base, $15 \mathrm{mM} \mathrm{NaCl}, \mathrm{pH}$ 8.0, 0.05\% Tween20) for 1 hour. PfDHS-GFP protein was immunodetected with 1:5000 dilutions of rabbit anti-GFP polyclonal antibody (Thermo Scientific \#PA1-19431) and goat anti-rabbit IgG antibody conjugated with HRP (\#SC-2004, Santa-Cruz, USA). Proteins were detected by chemiluminescence using Pierce ECL Western Blotting Substrate (Thermo Scientific). The intensity of the PfDHS-GFP band was measured by densitometry from the scanned image of the exposed X-ray film using the Image $\mathrm{J}$ program (Schneider, Rasband \& Eliceiri, 2012). The immunodetected protein band signals were normalized to total protein signal in each lane. The percent relative intensities of PfDHS-GFP are intensities in GlcN treatment conditions relative to the untreated control.

\section{Western immunoblot of PfDHFRTS-GFP and PfFC-GFP protein} PfFC_glmS, PfDHFR-TS_glmS and 3D7 parasites were cultured and synchronized as described above and harvested at the trophozoite stage. Parasites were liberated from erythrocytes by saponin lysis. Parasites were resuspended in 1X NuPAGE LDS sample buffer in 
216 a ratio of parasite cell/buffer volume of $2 \times 10^{6}$ parasites $/ \mathrm{mL}$ and incubated at $95^{\circ} \mathrm{C}$ for $10-15 \mathrm{~min}$

217 for protein extraction. Insoluble material was separated by centrifugation. Protein samples from

$2181 \times 10^{6}, 5 \times 10^{6}, 10 \times 10^{6}$ or $25 \times 10^{6}$ parasites were separated by electrophoresis as described above

219 for PfDHS-GFP Western immunoblot. Precision Plus Protein ${ }^{\mathrm{TM}}$ Dual Color Standards (Bio-Rad,

220 USA) were used as a protein ladder. Proteins were transferred to Immobilon-FL PVDF

221 membrane (Merck-Millipore) as described above for PfDHS-GFP Western immunoblot. After

222 transfer, membranes were stained with REVERT ${ }^{\mathrm{TM}}$ Total Protein Stain (LI-COR Biosciences,

223 USA). Total protein was visualized using an Odyssey ${ }^{\circledR}$ CLx system (LI-COR) in the $700 \mathrm{~nm}$

224 channel. After imaging, REVERT stain was removed by washing with REVERT Reversal

225 Solution (LI-COR) and water. The membrane was then incubated in Odyssey blocking buffer

226 (TBS) (LI-COR) for $1 \mathrm{hr}$ with $80 \mathrm{rpm}$ shaking. The blocked membrane was incubated in

227 Odyssey blocking buffer (TBS) with $0.2 \%$ (v/v) Tween 20 and 1:2,000 diluted rabbit anti-GFP

228 polyclonal antibody (\#G1544, Sigma) overnight with $80 \mathrm{rpm}$ shaking. The membrane was then

229 washed with 1X TBST (1X TBS with 0.05\% Tween 20) and incubated in Odyssey blocking

230 buffer (TBS) with 0.2\% Tween 20 and IRDye 800CW 1:20,000 diluted goat anti-rabbit IgG (LI-

231 COR) for 1 hour at room temperature in the dark. The membrane was scanned in the $800 \mathrm{~nm}$

232 channel and images were analyzed using Image Studio Software (LI-COR).

233

234 Hypusination assay

235

$10 \mathrm{~mL}$ P. falciparum sorbitol-synchronized cultures at approximately $2 \%$ hematocrit and $1 \%$ ring-stage parasitemia were treated with $0,2.5$ or $5.0 \mathrm{mM} \mathrm{GlcN}$ for $72 \mathrm{~h}$. Parasites were harvested and liberated from erythrocytes by saponin lysis. Parasite pellets were resuspended in $1 \%$ Triton-X100 in $1 \mathrm{X}$ PBS buffer and incubated at $4^{\circ} \mathrm{C}$ for $20 \mathrm{~min}$ to extract protein. Protein samples from approximately $5 \times 10^{6}$ parasites were separated by electrophoresis as described above for PfDHS-GFP Western immunoblot. Precision Plus Protein Kaleidoscope Prestained Protein Standards (Bio-Rad) were used as a protein ladder. Proteins were transferred to Immobilon-FL PVDF membrane (Merck-Millipore) and processed before detection with Odyssey CLx as described above. The blocked membrane was incubated in Odyssey blocking buffer (TBS) with $0.2 \%(\mathrm{v} / \mathrm{v})$ Tween 20 and 1:5,000 diluted rabbit anti-hypusine polyclonal 
246 then washed with 1X TBST (1X TBS with 0.05\% Tween 20) and incubated in Odyssey blocking

247 buffer (TBS) with $0.2 \%$ Tween 20 and IRDye 680RD Goat anti-Rabbit IgG (LI-COR) for 1 hour

248 at room temperature in the dark. The membrane was scanned in the $700 \mathrm{~nm}$ channel and images

249 were analyzed using Image Studio Software (LI-COR). Total protein loading in each lane was

250 quantified by the sum of pixels minus background in rectangular objects spanning polypeptides

251 15-150 kDa. The major band of hypusinated protein signal assumed to be PfeIF5A (17.6 kDa)

252 was normalized to the total protein signal in each lane and expressed relative to the control lane

253 (0 mM GlcN treatment).

254

255

\section{Nascent protein synthesis (puromycilation) assay}

256

257

Nascent protein synthesis was assessed using the puromycilation assay (Schmidt et al.,

258 2009). This assay is based on the incorporation of the translation inhibitor puromycin into

259 nascent peptide chains by actively translating ribosomes (Nathans, 1964). A previous report showed that this assay is suitable for P. falciparum (McLean \& Jacobs-Lorena, 2017). Synchronized $P$. falciparum cultures were treated with GlcN for $72 \mathrm{~h}$ as described above for hypusination assay. After GlcN treatment, puromycin (Sigma) was added to a final concentration of $5 \mu \mathrm{M}$ and parasites were incubated at $37^{\circ} \mathrm{C}$ for an additional $10 \mathrm{~min}$. The parasitized red blood cells were then washed with incomplete medium and parasites were liberated from erythrocytes by saponin lysis. Protein samples were obtained from approximately $5 \times 10^{6}$ parasites, separated by electrophoresis, transferred to PVDF membrane and processed before detection as described above for hypusination assay. After blocking, the membrane was incubated in Odyssey blocking buffer (TBS) with 0.2\% (v/v) Tween 20 and 1:10,000 diluted mouse anti-puromycin monoclonal antibody clone 12D10 (Merck-Millipore) for 1 hour with $80 \mathrm{rpm}$ shaking. The membrane was washed with $1 \mathrm{X}$ TBST (1X TBS with $0.05 \%$ Tween 20) and incubated in Odyssey blocking buffer (TBS) with $0.2 \%$ Tween 20, IRDye 800CW Goat anti-Mouse IgG (LI-COR) for 1 hour at room temperature in the dark. The membrane was washed with 1X TBST (1X TBS with 0.05\% Tween 20) and 1XTBS buffer before scanning in the $800 \mathrm{~nm}$ channel. Total protein and puromycilated peptides in each lane were quantified by the sum of pixels minus background in rectangular objects spanning polypeptides $15-150 \mathrm{kDa}$. The puromycilated peptide signal was 
276

277

278

279

280

281

282

283

284

285

286

287

288

289

290

291

292

293

294

295

296

297

298

299

300

301

302

303

304

305

normalized to the total protein signal in each lane and expressed relative to the control lane $(0$ $\mathrm{mM}$ GlcN treatment). The puromycilation assay was validated using P. falciparum synchronized cultures at mostly trophozoite stage. Parasites were pre-treated with growth-inhibitory compounds cycloheximide $(1,10$, or $100 \mu \mathrm{M})$; dihydroartemisinin $(0.01,0.10$, or $1 \mu \mathrm{M})$ and $\mathrm{GC7}(50,100$, or $1000 \mu \mathrm{M})$ for $1 \mathrm{~h}$ prior to puromycin exposure.

\section{Competitive growth assay}

P. falciparum transgenic parasite line PfFC_glmS was used as a control. The growth of a test transgenic line with riboswitch element integrated at a putative essential gene was normalized to that of the PfFC_glmS control. The control and test transgenic lines were first cultured separately and synchronized as described above. Ring-stage synchronized parasites were diluted to approximately $0.5 \%$ parasitemia. A new culture was established by combining control and test transgenic parasite cultures ( $5 \mathrm{~mL}$ of each) into the same culture plate. Samples were taken from the parasite co-culture every 4 days for 21 days (10 growth cycles). At each sampled time-point, the culture reached a parasitemia of approximately $2.5 \%$, consisting of mostly trophozoite stage parasites. The culture was then diluted to approximately $0.1 \%$ parasitemia in fresh medium. The parasite culture plates were placed in a refrigerator on "ring" days for 5-7 hours to maintain high synchronization (Yuan et al., 2014). Parasite pellets were harvested and used for genomic DNA extraction. The co-culture was conducted under standard and gene attenuation (2.5 or $5.0 \mathrm{mM} \mathrm{GlcN}$ inducer added) conditions, in which fresh GlcN was added after each time-point. The effect of GlcN on development of control parasites 3D7 and PfFC_glm $S$ was assessed by counting ring and trophozoite stage parasites separately from Giemsa-stained thin smears.

\section{Quantitative PCR assay of transgenic parasite ratios in competitive growth experiments}

Primers for quantitative PCR (qPCR) assays were designed to amplify specific discriminatory sequences in transgenic parasites tested in competitive growth assays. The discriminatory sequences spanned the fusion boundary between the $3^{\prime}$ end of the modified target 
306

307

308

309

310

311

312

313

314

315

316

317

318

319

320

321

322

323

324

325

326

327

328

329

330

331

332

333

334

335

gene and the GFP coding region. The LDH-F and LDH-R primers (Table S1; amplicon $221 \mathrm{bp}$ ) were also designed to amplify the PF3D7_1324900 (L-lactate dehydrogenase) gene, which is present at single copy in all parasites and is used for normalization of template DNA input. qPCR experiments were performed using a CFX96 Touch Real-Time PCR Detection System (Bio-Rad) and SsoFast EvaGreen Supermix (Bio-Rad) in $20 \mu \mathrm{L}$ reaction volumes, as recommended by the manufacturer. All primer pairs performed with similar efficiency (96$103 \%$, linear regression $\mathrm{R}^{2}>0.99$ ). Amplicons of the expected size were obtained only from the expected template genomic DNA, as assessed by agarose gel electrophoresis and melt-curve analysis. The PfDHS_glmS and PfDHS_M9 parasites were quantified from the DHS-GFP amplicon (188 bp, primers DHS-F and DHS-R; Table S1), the PfDHFR-TS-glmS parasite (Prommana et al., 2013) was quantified from the TS-GFP amplicon (190 bp, primers DHFRTS-F and DHFRTS-R; Table S1), and the PfFC-glmS parasite was quantified by the FC-GFP amplicon (125 bp, primers FC-F and FC-R; Table S1). The quantitative range of qPCR assays was determined using purified genomic DNA extracted from transgenic parasites that were mixed in different ratios (Fig. S3).

\section{Dose-response growth inhibition assays}

The growth of parasites was monitored under different concentrations of growth inhibitors in dose-response assays as described previously (Aroonsri et al., 2016). To assess the effect of GlcN on growth inhibition, parasites were co-treated with $2.5 \mathrm{mM} \mathrm{GlcN}$. The growth inhibitory compounds tested included $N^{1}$-guanyl-1,7-diaminoheptane (GC7, Sigma), cycloheximide (CYC, Sigma) and pyrimethamine (PYR, Sigma). Stock solutions of growth inhibitors were prepared fresh for each experiment, in which compounds were dissolved in DMSO (CYC and PYR) or culture medium (GC7). Compounds were diluted in culture medium, in which the maximum concentration of DMSO did not exceed $0.1 \%$. Control wells with no growth inhibitory compound contained $0.1 \%$ DMSO.

\section{Statistical analysis}


337

338

339

340

341

342

343

344

345

346

347

348

349

350

351

352

353

354

355

356

357

358

359

360

361

362

363

364

365

366

for Statistical Computing, Vienna, Austria., 2017). For analysis of Western immunoblot, hypusination and puromycilation assay data, Welch's two-tailed one-sample $t$-tests (Welch, 1947) were performed by testing the null hypothesis that sample means of test signal normalized to untreated control was not different from one. Tests with $P<0.05$ were considered significant.

The lme4 package (Bates et al., 2015) was used to perform a linear mixed effects analysis of the relationship between parasite growth and time in competitive growth assays. For validation experiments with 3D7 parental and PfFC-glmS control transgenic lines, the percentage of ring or trophozoite-infected cells was taken as the growth variable. In experiments with PfDHFR-TS-glmS, PfDHS_glmS and PfDHS_M9 transgenic parasites, growth relative to the PfFC-glm $S$ control transgenic parasite determined by qPCR was taken as the growth variable. GlcN treatment (with doses as factors) was modelled as a fixed effect. Individual parasite cultures grown on different days were modelled as random effects, with random intercepts included in the model for the effect on growth over time. Linear models were constructed from the data using Maximum Likelihood. The null model was that growth varies as a function of time. The full model was that growth varies as a function of time, with GlcN treatment and its interaction with time as fixed effects. Significant differences in model fitting were assessed by likelihood ratio test, with $P<0.05$ considered significant. Fitted models were plotted using the visreg package (Breheny \& Burchett, 2017).

Normalized growth values from dose-response assays were analysed using the drc package (Ritz \& Streibig, 2005). To allow proper comparison of $\mathrm{EC}_{50}$ values between the $-\mathrm{GlcN}$ and + GlcN conditions, the maximum and minimum growth values were assigned as shared and constant between the two conditions, such that only two parameters (slope and $\mathrm{EC}_{50}$ ) varied between the $-\mathrm{GlcN}$ and $+\mathrm{GlcN}$ conditions. $\mathrm{EC}_{50}$ ratios, associated S.Es and $t$-statistics were calculated from the two-variable parameter fitted models using the EDcomp function in the drc package. $\mathrm{EC}_{50}$ ratios were considered significant at $P<0.001$.

\section{In silico modelling of PfDHS protein structure and GC7 binding}


367

368

369

370

371

372

373

374

375

376

377

378

379

380

381

382

383

384

385

386

387

388

389

390

391

392

393

394

395

396

397

A three-dimensional structure of the PfDHS tetramer was constructed by the SWISSMODEL Server (Waterhouse et al., 2018). The program selected the X-ray crystal structure of Form I human DHS complexed with NAD as the homology template (Umland et al., 2004); PDB ID: 1RLZ). Ligand binding site identification and characterization was performed using SiteMap version 3.6, Schrödinger, LLC, New York (Halgren, 2009). The grid type was set as coarse and other settings were default. The putative ball-and-chain motif encompassing residues Ile30Pro45 of each PfDHS subunit was removed prior to ligand binding site analysis. Ligand binding sites with scores greater than 1.0 were considered significant. Molecular docking of GC7 at the substrate-binding pocket was performed using Glide (Friesner et al., 2004). A grid receptor was generated around the binding pocket with addition of void volume around NAD cofactor. The structure of Form II human DHS complexed with NAD and GC7 (Umland et al., 2004); PDB ID: 1RQD) was used for comparison of PfDHS and human DHS substrate binding pockets.

\section{Results}

Clonal transgenic P. falciparum parasite lines PfDHS_glmS and PfDHS_M9 were established with integration of $g \operatorname{lm} S$ riboswitch and the M9 inactive variant, respectively at the PfDHS encoding gene PF3D7_1412600. The DNA vectors used for integration also contain GFP gene sequence for C-terminal tagging of the target protein. Fluorescent parasites with GFP signal in the parasite cytoplasm were observed in ring, trophozoite and schizont stages for the PfDHS_glmS parasite (Fig. 1). Western immunoblotting with anti-GFP antibody revealed a species that migrated slightly larger than predicted for PfDHS-GFP fusion protein $(85.1 \mathrm{kDa})$ from PfDHS_glmS and PfDHS_M9 parasites (Fig. 2). PfDHS-GFP protein was significantly attenuated in the PfDHS_glmS parasite treated for $24 \mathrm{~h}$ with GlcN, with up to five-fold reduction observed with $5.0 \mathrm{mM}$ GlcN. In contrast, no significant reduction of PfDHS-GFP protein was observed with GlcN treatment in the PfDHS_M9 parasite with an inactive riboswitch.

Since the primary function of DHS enzyme in eukaryotes is hypusination of eIF5A protein, hypusination was quantified using a commercial anti-hypusine antibody in transgenic parasites. A major protein species $(<20 \mathrm{kDa})$ was detected by Western immunoblotting with this antibody, which matches the predicted molecular weight of $P$. falciparum eIF5A (17.6 kDa) and 
398 is the approximately the same size as PfeIF5A detected with anti-eIF5A antibodies (Foth et al., 399 2008). However, additional evidence, e.g. peptide mapping is needed to confirm that this species

400

401

402

403

404

405

406

407

408

409

410

411

412

413

414

415

416

417

418

419

420

421

422

423

424

425

426

427

428

is PfeIF5A. GlcN treatment led to significantly reduced hypusinated protein signal in

PfDHS_glmS parasites treated with GlcN compared with untreated controls, although this effect was rather small with $<30 \%$ mean reduction at $5.0 \mathrm{mM} \mathrm{GlcN}$ (Fig. 3). In contrast, GlcN treatment had no significant effect on hypusination in PfDHS_M9 parasites. We infer from this result that reduction of PfDHS expression leads to concomitant reduction of hypusinated protein. Hypusination is thought to be essential for the translation elongation function of this protein (Park et al., 2010). We tested whether reduced hypusination could affect protein synthesis by nascent protein synthesis (puromycilation) assay in PfDHS_glmS and PfDHS_M9 parasites. Nascent protein was quantified by the incorporation of puromycin into elongating peptide chains, detected as the signal from Western immunoblotting with anti-puromycin antibody. Short pretreatments of parasites with lethal $\left(>\mathrm{EC}_{50}\right)$ concentrations of $\mathrm{CYC}$ and DHA known to cause arrest of protein synthesis in P. falciparum (Hoepfner et al., 2012); (Rottmann et al., 2010); (Shaw et al., 2015); (McLean \& Jacobs-Lorena, 2017) led to markedly reduced puromycilation signal in both transgenic parasites, validating the assay (Fig. S5). Puromycilation signal was not significantly different in either parasite treated with $\mathrm{GlcN}$ for $72 \mathrm{~h}$ prior to puromycin labelling compared with parasites with no GlcN pre-treatment, suggesting that attenuation of PfDHS expression has little effect on the global translation level during this period (Fig. 3). Moreover, GlcN-treated parasites do not show any gross morphological defect (Fig. S6) and proliferation over $72 \mathrm{~h}$ is unaffected by GlcN (Fig. S7). These data suggest that the slight reduction of hypusination in parasites with attenuated PfDHS function is tolerated for short periods.

Although attenuation of PfDHS gene expression is not deleterious in the short term, prolonged loss of PfDHS activity could lead to a growth defect. In the standard growth assay, parasite cultures are initiated at low parasite density, e.g. $0.1 \%$ parasitemia, and growth assessed over the first two cycles (up to $96 \mathrm{~h}$ ). For some essential genes, $g \operatorname{lm} S$ riboswitch-mediated attenuation of expression can cause a significant growth defect under these conditions, e.g. PfDHFR-TS (Prommana et al., 2013), PfPTEX150 (Elsworth et al., 2014), PfRhopH2 (Counihan et al., 2017); (Ito, Schureck \& Desai, 2017) and PfRhopH3 (Ito, Schureck \& Desai, 2017).

However, $g \operatorname{lm} S$ riboswitch-mediated attenuation of other essential genes such as PfPMV (Sleebs 
429 et al., 2014) and PfFP3 (Xie et al., 2015) failed to show a growth defect in the standard growth

430 assay. The inability to detect growth defects in the standard growth assay is due to factors such

431 as insufficient attenuation, functional overlap/redundancy with related proteins and stage-specific

432 target protein function. For growth assays longer than two cycles, dilution of cells is necessary to

433 prevent overgrowth of controls. Transgenic parasites obtained by single cross-over

434 recombination must be maintained under a drug selective regimen, e.g. blasticidin, otherwise

435 they can be outgrown by wild-type revertants. To account for possible growth confounding effect

436 of the transgenic selective regimen, a control transgenic parasite (PfFC_glmS ) was created with

437 integration of the $g l m S$ riboswitch at the ferrochelatase (PfFC) gene. The PfFC gene is

438 dispensable during intra-erythrocytic stages, since the growth of clonal transgenic parasites with

439 knockout of this gene is not significantly different from wild-type (Ke et al., 2014); (Sigala et al.,

440 2015). We could not assess localization or riboswitch-mediated attenuation of PfFC-GFP protein

441 in the $P f F C \_g l m S$ parasite, since no green fluorescent $P f F C \_g l m S$ parasites were observed by

442 microscopy (Fig. S8), and the weak signal of putative PfFC-GFP protein was difficult to

443 distinguish from background in Western immunoblotting experiments (Fig. S9). We validated

444 the PfFC_glmS parasite as a control in growth experiments by assessing its growth in comparison

445 with 3D7 wild-type parasite under different GlcN treatments. Over the course of ten growth

446 cycles, treatment with 2.5 or $5.0 \mathrm{mM}$ GlcN has no significant effect on ring or trophozoite

447 development for both 3D7 and PfFC_glmS parasites (Fig. S10).

448

449

450

We established a competitive growth assay in which transgenic parasites are cultured for ten growth cycles. The extended growth period in this assay allows for detection of latent defects

451

452

453

454

455

456

457

458

459 that are apparent only after several growth cycles have elapsed. In this assay, a test transgenic parasite is co-cultured with the control PfFC_glmS transgenic parasite. The growth of test transgenic parasite was assessed by measuring the test:control transgenic parasite ratio by qPCR. The use of the control PfFC_glmS parasite allowed us to monitor growth without correction of dilution factors. Relative growth of the PfDHS_glmS parasite was significantly reduced under GlcN treatment (Fig. 4A). In contrast, GlcN had no significant effect on the relative growth of the PfDHS_M9 parasite (Fig 4B). Competitive growth assay of the PfDHFR-TS_glmS parasite revealed a more severe growth defect when treated with GlcN in which PfDHFR-TS_glmS parasites declined more rapidly (Fig. 4C). The results from competitive growth assays showed 
460 that attenuation of PfDHS expression causes a growth defect, indicating that this gene is likely to

461 be essential. As a further test of this gene's essentiality and validation as an antimalarial target, 462 chemogenomic profiling using antimalarial compounds was performed. In this approach, $g \operatorname{lm} S$

463 riboswitch-mediated attenuation of target gene expression sensitizes the parasite to antimalarials

464 acting on that target (Aroonsri et al., 2016). Chemogenomic profiling of transgenic parasites was 465 performed with growth-inhibitory compounds differing in their mode of action (Fig. 4D). The

466 PfDHS_glmS parasite is significantly more sensitive to GC7, a known inhibitor of PfDHS 467 enzyme activity in vitro (Kaiser et al., 2007), when co-treated with GlcN. We noted though that 468 the $\log _{2} \mathrm{EC}_{50}(-\mathrm{GlcN} /+\mathrm{GlcN})$ ratio is less than one for the PfDHS_glmS parasite. In contrast, the 469 PfDHS_M9 parasite is not significantly more sensitive to GC7 when co-treated with GlcN. GlcN 470 co-treatment does not significantly increase the sensitivity of either parasite to control drugs 471 which do not target the PfDHS, including CYC, a known inhibitor of the ribosome (Obrig et al., 472 1971); (Schneider-Poetsch et al., 2010), and PYR, which targets PfDHFR-TS (Aroonsri et al., 473 2016).

474

In order to assess the feasibility of PfDHS as a target for rationally designed inhibitors, structural study was performed. A three-dimensional structure of PfDHS was constructed by 477 homology modeling using a human DHS crystal structure (Fig. 5). The quality of the PfDHS 478 structure core is estimated to be high with most residues showing QMEAN scores greater than 0.7. The periphery of the PfDHS structure is of lower estimated quality owing to inserts not present in the human DHS protein (Fig. S12). Ligand binding site analysis identified two binding sites with significantly high scores. The top-scoring site with a site score of 1.16 corresponds to the putative substrate binding pocket occupied by spermidine or a competitive inhibitor such as GC7. The tetramer substrate binding pockets are arranged in a sandwich homodimer manner with two sites per homodimer interface (Fig. 6A, B). The substrate binding pockets in each PfDHS subunit are connected in a tunnel-like fashion highly similar to human DHS (Fig. 6C).

486 Comparison of residues in the vicinity of the substrate binding pocket between PfDHS and 487 human DHS revealed conservation of key interacting residues in PfDHS including Asp368, Asn420, Gly442, Ser443, and Glu451 (Fig. 6D). SiteMap also identified other residues conserved between human and PfDHS that may interact with GC7, or contribute to the 490 environment favorable for GC7 binding (Fig. 6E, F). SiteMap detected a second ligand binding 
491 site in PfDHS with a site score of 1.01. This site is located in-between the two insertion loops of

492 PfDHS and adjacent to a putative ball-and-chain motif (Fig. S13). The ball-and-chain motif

493 regulates access to the substrate binding pocket, and becomes disordered upon substrate or

494 inhibitor binding (Liao et al., 1998); (Umland et al., 2004).

495

496

Hypusinated eIF5A is thought to be important for translation elongation at poorly

497

translated codons, especially consecutive proline-coding codons (Dever, Gutierrez \& Shin, 2014). Polyproline motifs are numerous in unicellular eukaryotes such as Saccharomyces cerevisiae yeast with 769 genes containing PPP or PPG coding motifs (Mandal, Mandal \& Park, 500 2014). Moreover, 136/1110 of yeast essential genes (Zhang, 2004) contain polyproline coding

501

502

503

504

505

506

507

508

509

510

511

512

513

\section{4}

515

516

517

518

519

520

521 motifs. The essential genes with polyproline motifs therefore represent 136/5175 (2.6\%) of the total yeast protein-coding genes. We therefore performed a bioinformatic survey of the $P$. falciparum proteome for proteins with polyproline motifs that may require hypusinated eIF5A for optimal synthesis following a previous rationale (Mandal, Mandal \& Park, 2014). 257 proteins with PPP or PPG motifs were found (Table S2), of which insertions of piggyBac transposon are not tolerated in the corresponding coding regions for 128 genes (Zhang et al., 2018). Using the rationale that $P$. falciparum genes devoid of piggyBac transposon insertions are essential, 128/2680 essential genes thus contain polyproline-coding motifs. The essential genes with polyproline motifs in P. falciparum therefore represent a similar proportion of the total protein coding genes $(128 / 5305 ; 2.4 \%)$ as in yeast. Among the 142 orthologous genes also with polyproline coding motifs in $P$. berghei, 58 are essential, 16 cause slow growth when disrupted, and 18 are dispensable (Bushell et al., 2017).

\section{Discussion}

Hypusine modification of eIF5A is essential in different eukaryotic organisms. In this study, we have validated the DHS enzyme, which is responsible for the first step in the hypusination pathway, as an antimalarial target in $P$. falciparum. We created transgenic parasites with modification of the PfDHS gene for phenotypic study. The modification included a Cterminal GFP tag, which facilitated monitoring of PfDHS protein. Confocal microscopy revealed a cytoplasmic localization of GFP-tagged PfDHS protein, which is consistent with the 
522 localization of the mammalian DHS protein (Sievert et al., 2012). The cytoplasmic localization

523 may be important to localize eIF5A protein, as DHS-knockout mice show accumulation of

524 nuclear eIF5A (Pällmann et al., 2015). We were able to attenuate PfDHS expression

525 approximately five-fold in the PfDHS_glmS parasite with similar efficiency to that obtained for

526 other essential genes using the same reverse-genetic system (Prommana et al., 2013); (Sleebs et

527 al., 2014); (Elsworth et al., 2014); (Xie et al., 2015); (Counihan et al., 2017); (Thériault \&

528 Richard, 2017). The attenuation of PfDHS expression in this transgenic parasite is specifically

529 induced by GlcN treatment, since GlcN does not reduce expression of the same gene in the

530 PfDHS_M9 parasite, which differs only by two nucleotide substitutions at the glmS riboswitch

531 cleavage site that nullify RNA self-cleavage (Winkler et al., 2004).

532

533

Attenuation of PfDHS expression in the PfDHS_glmS causes a growth defect, although

534 the decline of PfDHS_glmS parasites in culture is less rapid than PfDHFR-TS-attenuated

535 parasites. These data suggest that PfDHS is essential and explain why no insertions of piggyBac

536 transposon are tolerated in this gene (Zhang et al., 2018). However, inducible null mutants (e.g.

537 created by using the DiCre inducible knockout method [Collins et al., 2013]) are required for

538 definitive proof of essentiality. The slow decline of PfDHS-attenuated parasites suggests that the

539 residual hypusinated protein is sufficient to support viability for at least one growth cycle,

540 perhaps because hypusinated protein is long-lived. In support of this explanation, the level of

541 hypusinated protein in PfDHS-attenuated parasites is modestly reduced. $60 \%$ reduction of

542 hypusinated eIF5A in a conditional mutant of yeast with attenuated DHS expression is

543 deleterious (Galvão et al., 2013), suggesting that a certain level of hypusinated eIF5A is

544 necessary for eukaryote cell growth. Alternatively, the growth defect in PfDHS-attenuated

545 parasites could be due to loss of hypusination and/or a "moonlighting" function of PfDHS. To

546 test possible "moonlighting" functions of PfDHS, data from catalytically inactive PfDHS

547 mutants are required. Although the slow decline of PfDHS-attenuated parasites could be

548 attributed to incomplete attenuation of PfDHS expression, decline of null PfDHS mutants in

549 growth assays may not be much more rapid since null DHS mutants of yeast can undergo several

550 cell divisions before arrest (Park, Joe \& Kang, 1998). 
552

553

554

555

556

557

558

559

560

561

562

563

564

565

566

567

568

569

570

571

572

573

574

575

576

577

578

579

580

581

582

The competitive growth assay developed in this study is suitable for monitoring of growth over extended periods and demonstrating latent (more than two growth cycles) growth defects. Our method has the advantage that no correction for dilution factors is necessary, which could introduce substantial error. However, we have not performed head to head comparisons of the competitive growth assay with other methods to assess accuracy. The competitive growth assay could be scaled-up by pooling parasites with $g \operatorname{lm} S$ riboswitch modifications of different genes and monitoring the growth of each mutant by next-generation sequencing, similar to that described for mutants carrying piggyBac insertions (Bronner et al., 2016). The competitive growth assay is an alternative to the plaque-based growth assay, which has been used to demonstrate latent growth defects in essential invasion genes (Thomas et al., 2016). The small size of plaques make quantification difficult, especially if a scanner of sufficiently high resolution is not available. Slow growing mutant parasites may also have failed to reach a sufficiently critical mass at the end of the assay period such that no plaque is visible and the growth defect over-estimated. The growth defects of mutant parasites inferred from plaque assay can be confounded by competition with wild-type parasites (Lehmann et al., 2018). Furthermore, the plaque-based growth assay is an end-point assay and so cannot provide information of growth dynamics like the competitive growth assay.

From the latent growth defect in PfDHS mutants, PfDHS can be considered a less vulnerable antimalarial target than other essential genes such as PfDHFR-TS. Information of target vulnerability is important for antimalarial development. It may be difficult to develop potent antimalarial derivatives from hit compounds obtained by high throughput screening if the target has a low vulnerability. This is because inhibitors of less vulnerable targets need to bind the target with very high affinity to ensure that almost all target activity is inhibited at therapeutic doses for antimalarial efficacy. In contrast, compounds against the most vulnerable targets (for which even small reductions in activity are deleterious to the parasite) may only need to have moderate binding affinity for high antimalarial efficacy. Furthermore, knowledge of target vulnerability could be important for consideration of how easily resistance could evolve. Resistance mutations in less vulnerable targets that cause a small reduction of inhibitor binding affinity could render drugs ineffective. If a panel of mutants with the expression of different essential genes attenuated using the $g \operatorname{lm} S$ riboswitch or another reverse genetic tool was 
583 available, competitive growth assays could be performed to systematically compare target

584 vulnerabilities and triage targets for antimalarial development.

585

586

587

PfDHS-attenuated parasites are significantly more sensitive to growth inhibition by GC7, suggesting that the primary in vivo target of this compound is PfDHS. The slow decline of 588 genetically attenuated PfDHS parasites in competitive growth assays suggests that some of the 589 antimalarial effect of GC7 observed in standard antimalarial assays, in which growth is assessed over shorter periods, could be attributed to inhibition of secondary targets (off-targeting). The $\log _{2} \mathrm{EC}_{50}(-\mathrm{GlcN} /+\mathrm{GlcN})$ ratio for GC7 against the PfDHS_glmS parasite is markedly lower than the ratios for antifolates against the PfDHFR-TS_glmS parasite (Aroonsri et al., 2016). Low EC 50 ratios are consistent with off-targeting. In support of this inference, GC7 has reported off-target effects in human cells, including induction of autophagy independently of eIF5A activity (Oliverio et al., 2014). Alternatively, the low $\mathrm{EC}_{50}$ ratio for GC7 against the PfDHS_glmS parasite may not be due to off-targeting if the level of PfDHS remaining in the + GlcN condition is still in excess of what is required for growth.

598

The inference that PfDHS is the primary antimalarial target of GC7 is supported by the in silico modelling data, which show conservation of substrate binding pocket and PfDHS residues putatively involved with GC7 interaction. The high conservation of substrate binding pocket could make the design of antimalarials specific to the PfDHS target challenging. However, the modelled PfDHS structure reveals a second potential ligand binding site that could also be exploited for rational drug design. The second site overlaps insert residues not present in human DHS and a putative ball-and-chain motif. Compounds binding to this site thus could act as allosteric inhibitors by preventing access of protein substrates to the substrate binding pocket for deoxyhypusine modification. X-ray structural data of PfDHS could provide important insights into PfDHS for drug design not revealed by in silico modelling, including the roles of the balland-chain motif and inserts peripheral to the core. polyproline motifs may be conserved in $P$. falciparum, as a number of its proteins contain these 
614 number of these proteins that are essential with respect to the total protein complement is similar.

615 Insufficient synthesis of one or more essential protein could be responsible for the growth defect 616 in PfDHS attenuated mutants, although proteomic data are needed to test this hypothesis. The 617 small number of polyproline motif proteins in P. falciparum that potentially require hypusinated 618 PfeIF5A for their production could explain why global protein synthesis (in the short term) is not 619 significantly reduced when PfDHS function is attenuated.

620

\section{Conclusions}

622

623

The loss of PfDHS function leads to a growth defect, suggesting that this gene is essential. However, definitive proof from null mutants is required to conclude essentiality. Loss 625 of PfDHS function leads to reduction of hypusination, which may affect synthesis of some 626 proteins. PfDHS is not as vulnerable a target as other essential genes such as PfDHFR-TS, although it can be targeted by antimalarials such as GC7.

628

629

\section{References}

Aroonsri A, Akinola O, Posayapisit N, Songsungthong W, Uthaipibull C, Kamchonwongpaisan S, Gbotosho GO, Yuthavong Y, Shaw PJ. 2016. Identifying antimalarial compounds targeting dihydrofolate reductase-thymidylate synthase (DHFR-TS) by chemogenomic profiling. International Journal for Parasitology. DOI: 10.1016/j.ijpara.2016.04.002.

Bates D, Mächler M, Bolker B, Walker S. 2015. Fitting Linear Mixed-Effects Models Using 636 lme4. Journal of Statistical Software 67. DOI: 10.18637/jss.v067.i01.

Breheny P, Burchett W. 2017. Visualization of Regression Models Using visreg. The R Journal 9:56-71. DOI: 10.32614/RJ-2017-046. 
641

642

643

644

645

646

647

648

649

650

651

652

653

654

655

656

657

658

659

660

661

662

663

phenotyping of transposon mutants. Genome Research: 26:980-989. DOI:

10.1101/gr.200279.115.

Bushell E, Gomes AR, Sanderson T, Anar B, Girling G, Herd C, Metcalf T, Modrzynska K, Schwach F, Martin RE, Mather MW, McFadden GI, Parts L, Rutledge GG, Vaidya AB, Wengelnik K, Rayner JC, Billker O. 2017. Functional Profiling of a Plasmodium Genome Reveals an Abundance of Essential Genes. Cell 170:260-272.e8. DOI: 10.1016/j.cell.2017.06.030.

Clark K, Niemand J, Reeksting S, Smit S, van Brummelen AC, Williams M, Louw AI, Birkholtz L. 2010. Functional consequences of perturbing polyamine metabolism in the malaria parasite, Plasmodium falciparum. Amino Acids 38:633-644. DOI: 10.1007/s00726-0090424-7.

Collins CR, Das S, Wong EH, Andenmatten N, Stallmach R, Hackett F, Herman J-P, Müller S, Meissner M, Blackman MJ. 2013. Robust inducible Cre recombinase activity in the human malaria parasite Plasmodium falciparum enables efficient gene deletion within a single asexual erythrocytic growth cycle: Conditional Cre in the human malaria parasite. Molecular Microbiology 88:687-701. DOI: 10.1111/mmi.12206.

Counihan N, Chisholm SA, Bullen HE, Srivastava A, Sanders PR, Jonsdottir TK, Weiss GE, Ghosh S, Crabb BS, Creek DJ, Gilson PR, de Koning-Ward TF. 2017. Plasmodium falciparum parasites deploy RhopH2 into the host erythrocyte to obtain nutrients, grow and replicate. eLife 6:e23217. DOI: 10.7554/eLife.23217.

Cranmer SL, Magowan C, Liang J, Coppel RL, Cooke BM. 1997. An alternative to serum for cultivation of Plasmodium falciparum in vitro. Transactions of the Royal Society of Tropical Medicine and Hygiene 91:363-365. DOI: 10.1016/S0035-9203(97)90110-3. 
664 Deitsch K, Driskill C, Wellems T. 2001. Transformation of malaria parasites by the spontaneous

665 uptake and expression of DNA from human erythrocytes. Nucleic Acids Research

666 29:850-853. DOI: 10.1093/nar/29.3.850.

667

668

669

670

671

672

673

674

675

676

677

678

679

680

681

682

683

684

685

686

Dever TE, Gutierrez E, Shin B-S. 2014. The hypusine-containing translation factor eIF5A. Critical Reviews in Biochemistry and Molecular Biology 49:413-425. DOI: 10.3109/10409238.2014.939608.

Elsworth B, Matthews K, Nie CQ, Kalanon M, Charnaud SC, Sanders PR, Chisholm SA, Counihan NA, Shaw PJ, Pino P, Chan J-A, Azevedo MF, Rogerson SJ, Beeson JG, Crabb BS, Gilson PR, de Koning-Ward TF. 2014. PTEX is an essential nexus for protein export in malaria parasites. Nature 511:587-591. DOI: 10.1038/nature13555.

Friesner RA, Banks JL, Murphy RB, Halgren TA, Klicic JJ, Mainz DT, Repasky MP, Knoll EH, Shelley M, Perry JK, Shaw DE, Francis P, Shenkin PS. 2004. Glide: A New Approach for Rapid, Accurate Docking and Scoring. 1. Method and Assessment of Docking Accuracy. Journal of Medicinal Chemistry 47:1739-1749. DOI: 10.1021/jm0306430.

Galvão FC, Rossi D, Silveira W da S, Valentini SR, Zanelli CF. 2013. The Deoxyhypusine Synthase Mutant dys1-1 Reveals the Association of eIF5A and Asc1 with Cell Wall Integrity. PLoS ONE 8:e60140. DOI: 10.1371/journal.pone.0060140.

Halgren TA. 2009. Identifying and characterizing binding sites and assessing druggability. Journal of Chemical Information and Modeling 49:377-389. DOI: 10.1021/ci800324m.

Hoepfner D, McNamara CW, Lim CS, Studer C, Riedl R, Aust T, McCormack SL, Plouffe DM, Meister S, Schuierer S, Plikat U, Hartmann N, Staedtler F, Cotesta S, Schmitt EK, Petersen F, Supek F, Glynne RJ, Tallarico JA, Porter JA, Fishman MC, Bodenreider C, Diagana TT, Movva NR, Winzeler EA. 2012. Selective and Specific Inhibition of the 
687 688 689 690 691 692 693 694 695 696 697 698

Plasmodium falciparum Lysyl-tRNA Synthetase by the Fungal Secondary Metabolite Cladosporin. Cell Host \& Microbe 11:654-663. DOI: 10.1016/j.chom.2012.04.015.

Ito D, Schureck MA, Desai SA. 2017. An essential dual-function complex mediates erythrocyte invasion and channel-mediated nutrient uptake in malaria parasites. eLife 6:e23485. DOI: 10.7554/eLife. 23485 .

Kaiser A, Gottwald A, Wiersch C, Lindenthal B, Maier W, Seitz HM. 2001. Effect of drugs inhibiting spermidine biosynthesis and metabolism on the in vitro development of Plasmodium falciparum. Parasitology Research 87:963-972. DOI: $10.1007 / \mathrm{s} 004360100460$.

Kaiser A, Hammels I, Gottwald A, Nassar M, Zaghloul MS, Motaal BA, Hauber J, Hoerauf A. 2007. Modification of eukaryotic initiation factor 5A from Plasmodium vivax by a truncated deoxyhypusine synthase from Plasmodium falciparum: An enzyme with dual enzymatic properties. Bioorganic \& Medicinal Chemistry 15:6200-6207. DOI: 10.1016/j.bmc.2007.06.026.

Ke H, Sigala PA, Miura K, Morrisey JM, Mather MW, Crowley JR, Henderson JP, Goldberg DE, Long CA, Vaidya AB. 2014. The heme biosynthesis pathway is essential for Plasmodium falciparum development in mosquito stage but not in blood stages. The Journal of Biological Chemistry 289:34827-34837. DOI: 10.1074/jbc.M114.615831.

Kersting D, Krüger M, Sattler JM, Mueller A-K, Kaiser A. 2016. A suggested vital function for eIF-5A and dhs genes during murine malaria blood-stage infection. FEBS open bio 6:860-872. DOI: 10.1002/2211-5463.12093.

Lambros C, Vanderberg JP. 1979. Synchronization of Plasmodium falciparum erythrocytic stages in culture. The Journal of Parasitology 65:418-420. DOI: 10.2307/3280287. 
710 Lehmann C, Tan MSY, de Vries LE, Russo I, Sanchez MI, Goldberg DE, Deu E. 2018.

711 Plasmodium falciparum dipeptidyl aminopeptidase 3 activity is important for efficient

712

713

714

715

716

717

718

719

720

721

722

723

724

725

726

727

728

729

730

731

732 erythrocyte invasion by the malaria parasite. PLOS Pathogens 14:e1007031. DOI: 10.1371/journal.ppat.1007031.

Liao DI, Wolff EC, Park MH, Davies DR. 1998. Crystal structure of the NAD complex of human deoxyhypusine synthase: an enzyme with a ball-and-chain mechanism for blocking the active site. Structure 6:23-32. DOI: 10.1016/S0969-2126(98)00004-5.

Mandal A, Mandal S, Park MH. 2014. Genome-Wide Analyses and Functional Classification of Proline Repeat-Rich Proteins: Potential Role of eIF5A in Eukaryotic Evolution. PLoS ONE 9:e111800. DOI: 10.1371/journal.pone.0111800.

McLean KJ, Jacobs-Lorena M. 2017. Plasmodium falciparum Maf1 Confers Survival upon Amino Acid Starvation. mBio 8:e2317-16. DOI: 10.1128/mBio.02317-16.

Molitor IM, Knöbel S, Dang C, Spielmann T, Alléra A, König GM. 2004. Translation initiation factor eIF-5A from Plasmodium falciparum. Molecular and Biochemical Parasitology 137:65-74. DOI: 10.1016/j.molbiopara.2004.04.013.

Nathans D. 1964. Puromycin inhibition of protein synthesis: incorporation of puromycin into peptide chains. Proceedings of the National Academy of Sciences of the United States of America 51:585-592. DOI: 10.1073/pnas.51.4.585.

Obrig TG, Culp WJ, McKeehan WL, Hardesty B. 1971. The mechanism by which cycloheximide and related glutarimide antibiotics inhibit peptide synthesis on reticulocyte ribosomes. The Journal of Biological Chemistry 246:174-181.

Oliverio S, Corazzari M, Sestito C, Piredda L, Ippolito G, Piacentini M. 2014. The spermidine analogue GC7 (N1-guanyl-1,7-diamineoheptane) induces autophagy through a 
mechanism not involving the hypusination of eIF5A. Amino Acids 46:2767-2776. DOI:

734

735

736

737

738

739

740

741

742

743

744

745

746

747

748

749

750

751

752

753

754

755 10.1007/s00726-014-1821-0.

Pällmann N, Braig M, Sievert H, Preukschas M, Hermans-Borgmeyer I, Schweizer M, Nagel CH, Neumann M, Wild P, Haralambieva E, Hagel C, Bokemeyer C, Hauber J, Balabanov S. 2015. Biological Relevance and Therapeutic Potential of the Hypusine Modification System. Journal of Biological Chemistry 290:18343-18360. DOI: 10.1074/jbc.M115.664490.

Park MH, Joe YA, Kang KR. 1998. Deoxyhypusine Synthase Activity Is Essential for Cell Viability in the Yeast Saccharomyces cerevisiae. Journal of Biological Chemistry 273:1677-1683. DOI: 10.1074/jbc.273.3.1677.

Park MH, Nishimura K, Zanelli CF, Valentini SR. 2010. Functional significance of eIF5A and its hypusine modification in eukaryotes. Amino Acids 38:491-500. DOI: 10.1007/s00726009-0408-7.

Prommana P, Uthaipibull C, Wongsombat C, Kamchonwongpaisan S, Yuthavong Y, Knuepfer E, Holder AA, Shaw PJ. 2013. Inducible Knockdown of Plasmodium Gene Expression Using the glmS Ribozyme. PLoS ONE 8:e73783. DOI: 10.1371/journal.pone.0073783.

R Core Team. 2017. R Foundation for Statistical Computing, Vienna, Austria. 2017. R: a language and environment for statistical computing. Available at https://www.rproject.org/ (accessed 1 February 2019)

Ritz C, Streibig JC. 2005. Bioassay analysis using R. Journal of Statistical Software 12:1-22. DOI: $10.18637 /$ jss.v012.i05.

Rottmann M, McNamara C, Yeung BKS, Lee MCS, Zou B, Russell B, Seitz P, Plouffe DM, Dharia NV, Tan J, Cohen SB, Spencer KR, Gonzalez-Paez GE, Lakshminarayana SB, 
756

757

758

759

760

761

762

763

764

765

766

767

768

769

770

771

772

773

774

775

776

777

778

Goh A, Suwanarusk R, Jegla T, Schmitt EK, Beck H-P, Brun R, Nosten F, Renia L, Dartois V, Keller TH, Fidock DA, Winzeler EA, Diagana TT. 2010. Spiroindolones, a Potent Compound Class for the Treatment of Malaria. Science 329:1175-1180. DOI: 10.1126/science. 1193225 .

Schmidt EK, Clavarino G, Ceppi M, Pierre P. 2009. SUnSET, a nonradioactive method to monitor protein synthesis. Nature Methods 6:275-277. DOI: 10.1038/nmeth.1314.

Schneider CA, Rasband WS, Eliceiri KW. 2012. NIH Image to ImageJ: 25 years of image analysis. Nature Methods 9:671-675. DOI: 10.1038/nmeth.2089.

Schneider-Poetsch T, Ju J, Eyler DE, Dang Y, Bhat S, Merrick WC, Green R, Shen B, Liu JO. 2010. Inhibition of eukaryotic translation elongation by cycloheximide and lactimidomycin. Nature Chemical Biology 6:209-217. DOI: 10.1038/nchembio.304.

Shaw PJ, Chaotheing S, Kaewprommal P, Piriyapongsa J, Wongsombat C, Suwannakitti N, Koonyosying P, Uthaipibull C, Yuthavong Y, Kamchonwongpaisan S. 2015. Plasmodium parasites mount an arrest response to dihydroartemisinin, as revealed by whole transcriptome shotgun sequencing (RNA-seq) and microarray study. BMC Genomics 16. DOI: 10.1186/s12864-015-2040-0.

Sievert H, Venz S, Platas-Barradas O, Dhople VM, Schaletzky M, Nagel C-H, Braig M, Preukschas M, Pällmann N, Bokemeyer C, Brümmendorf TH, Pörtner R, Walther R, Duncan KE, Hauber J, Balabanov S. 2012. Protein-protein-interaction Network Organization of the Hypusine Modification System. Molecular \& Cellular Proteomics 11:1289-1305. DOI: 10.1074/mcp.M112.019059.

Sigala PA, Crowley JR, Henderson JP, Goldberg DE. 2015. Deconvoluting heme biosynthesis to target blood-stage malaria parasites. eLife 4:e09143. DOI: 10.7554/eLife.09143. 
779 Sleebs BE, Lopaticki S, Marapana DS, O’Neill MT, Rajasekaran P, Gazdik M, Günther S,

780 Whitehead LW, Lowes KN, Barfod L, Hviid L, Shaw PJ, Hodder AN, Smith BJ,

781 Cowman AF, Boddey JA. 2014. Inhibition of Plasmepsin V Activity Demonstrates Its

782 Essential Role in Protein Export, PfEMP1 Display, and Survival of Malaria Parasites.

783 PLoS Biology 12:e1001897. DOI: 10.1371/journal.pbio.1001897.

784

785

786

787

788

789

790

791

792

793

794

795

796

797

798

799

800

801

Teng R, Junankar PR, Bubb WA, Rae C, Mercier P, Kirk K. 2009. Metabolite profiling of the intraerythrocytic malaria parasite Plasmodium falciparum by ${ }^{1} \mathrm{H}$ NMR spectroscopy. NMR in Biomedicine 22:292-302. DOI: 10.1002/nbm.1323.

Thériault C, Richard D. 2017. Characterization of a putative Plasmodium falciparum SAC1 phosphoinositide-phosphatase homologue potentially required for survival during the asexual erythrocytic stages. Scientific Reports 7:12710. DOI: 10.1038/s41598-01712762-0.

Thomas JA, Collins CR, Das S, Hackett F, Graindorge A, Bell D, Deu E, Blackman MJ. 2016. Development and Application of a Simple Plaque Assay for the Human Malaria Parasite Plasmodium falciparum. PLOS ONE 11:e0157873. DOI: 10.1371/journal.pone.0157873.

Trager W, Jensen JB. 1976. Human malaria parasites in continuous culture. Science 193:673675. DOI: $10.1126 /$ science. 781840 .

Umland TC, Wolff EC, Park MH, Davies DR. 2004. A new crystal structure of deoxyhypusine synthase reveals the configuration of the active enzyme and of an enzyme.NAD.inhibitor ternary complex. The Journal of Biological Chemistry 279:28697-28705. DOI: 10.1074/jbc.M404095200.

Waterhouse A, Bertoni M, Bienert S, Studer G, Tauriello G, Gumienny R, Heer FT, de Beer TAP, Rempfer C, Bordoli L, Lepore R, Schwede T. 2018. SWISS-MODEL: homology 
802

803

804

805

806

807

808

809

810

811

812

813

814

815

816

817

818

819

820

821

822

823

824

modelling of protein structures and complexes. Nucleic Acids Research 46:W296-W303. DOI: $10.1093 /$ nar/gky427.

Welch BL. 1947. The generalization of 'Student's' problem when several different population variances are involved. Biometrika 34:28-35. DOI: 10.1093/biomet/34.1-2.28.

Winkler WC, Nahvi A, Roth A, Collins JA, Breaker RR. 2004. Control of gene expression by a natural metabolite-responsive ribozyme. Nature 428:281-286. DOI: 10.1038/nature02362.

Woodrow CJ, White NJ. 2016. The clinical impact of artemisinin resistance in Southeast Asia and the potential for future spread. FEMS Microbiology Reviews 41:34-48. DOI: 10.1093/femsre/fuw037.

World Health Organization. 2016. World malaria report 2016. Geneva: World Health Organization.

Wu Y, Sifri CD, Lei HH, Su XZ, Wellems TE. 1995. Transfection of Plasmodium falciparum within human red blood cells. Proceedings of the National Academy of Sciences of the United States of America 92:973-977. DOI: 10.1073/pnas.92.4.973.

Xie SC, Dogovski C, Hanssen E, Chiu F, Yang T, Crespo MP, Stafford C, Batinovic S, Teguh S, Charman S, Klonis N, Tilley L. 2015. Haemoglobin degradation underpins the sensitivity of early ring stage Plasmodium falciparum to artemisinins. Journal of Cell Science. DOI: $10.1242 /$ jcs. 178830 .

Yuan L, Hao M, Wu L, Zhao Z, Rosenthal BM, Li X, He Y, Sun L, Feng G, Xiang Z, Cui L, Yang Z. 2014. Refrigeration provides a simple means to synchronize in vitro cultures of Plasmodium falciparum. Experimental Parasitology 140:18-23. DOI:

10.1016/j.exppara.2014.03.010. 
825 Zhang R. 2004. DEG: a database of essential genes. Nucleic Acids Research 32:271D-272. DOI:

826 10.1093/nar/gkh024.

827 Zhang M, Wang C, Otto TD, Oberstaller J, Liao X, Adapa SR, Udenze K, Bronner IF, Casandra

828 D, Mayho M, Brown J, Li S, Swanson J, Rayner JC, Jiang RHY, Adams JH. 2018.

829 Uncovering the essential genes of the human malaria parasite Plasmodium falciparum by

830 saturation mutagenesis. Science 360:eaap7847. DOI: 10.1126/science.aap7847.

831

832 
Figure 1

PfDHS protein localization in transgenic parasites.

Representative confocal microscopic images of PfDHS_glmS parasites expressing GFP-tagged PfDHS protein at ring, trophozoite and schizont stages. Parasite nuclei were stained with Hoechst 33342. Composite images from merging Hoechst and GFP fluorescence signals with the Bright-field image are shown in the panels on the far-right. Scale bars $=5 \mu \mathrm{m}$. 
Bright field

Ring

\section{Trophozoite}

Schizont
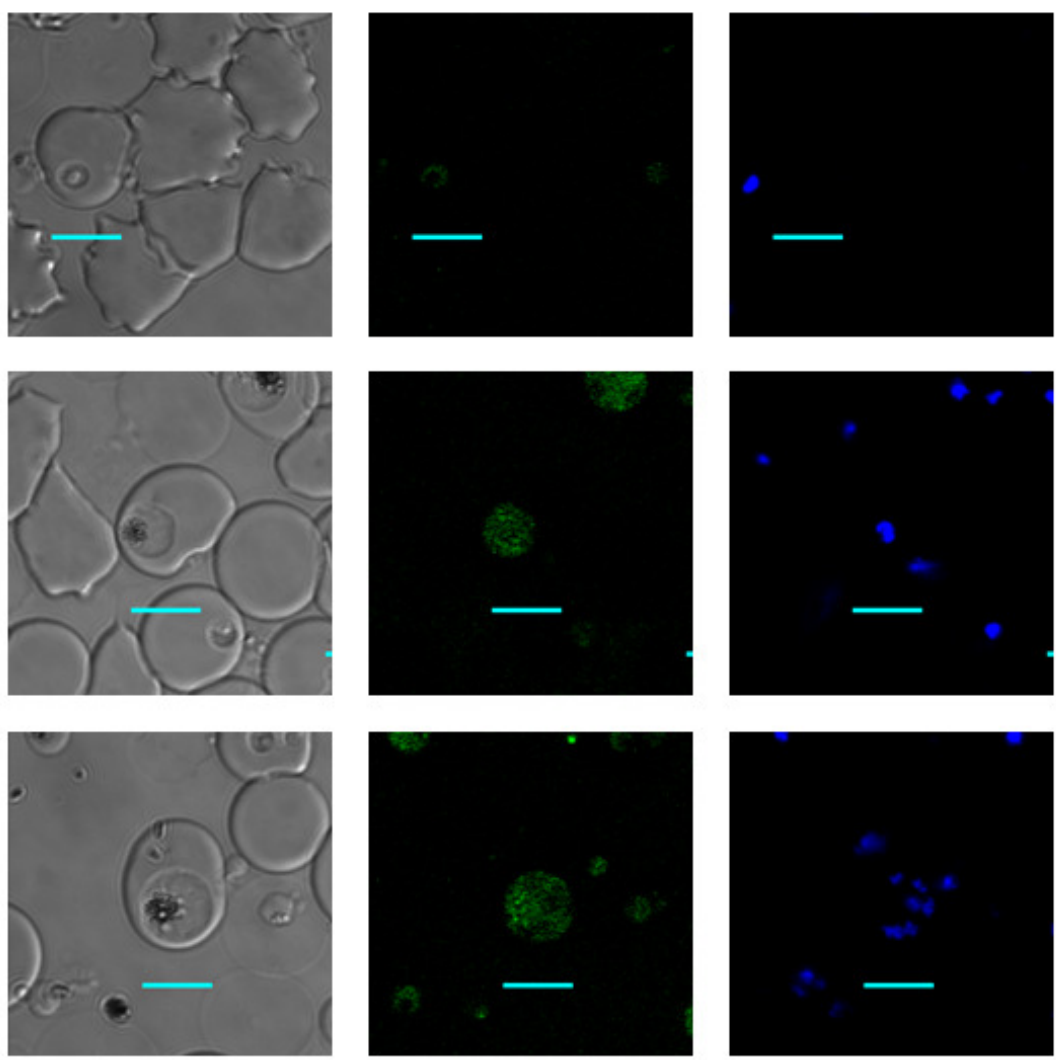
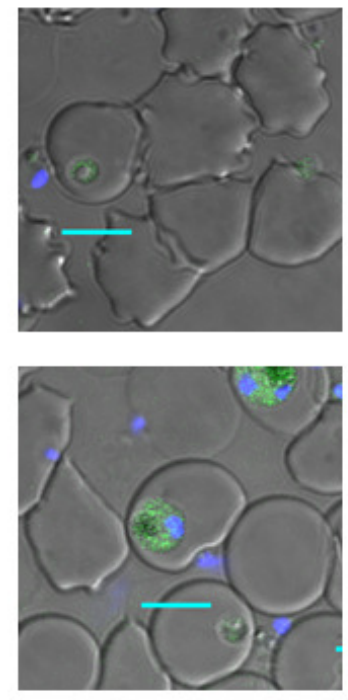

Merge all

Hoechst

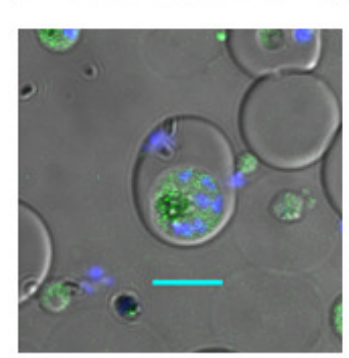




\section{Figure 2}

\section{Attenuation of PfDHS expression in transgenic parasites.}

(A) Representative Western immunoblot results from detection of GFP-tagged PfDHS protein (PfDHS-GFP) in PfDHS_glmS and PfDHS_M9 transgenic parasites. Soluble protein extracts were obtained from approximately $10 \times 10^{6}$ parasites treated for $24 \mathrm{~h}$ with $0,1.25,2.50$ and $5.00 \mathrm{mM}$ glucosamine (GlcN). Proteins were separated in $4-12 \%$ NuPAGE gel and transferred to PVDF membrane. Total protein was stained on the membrane using Ponceau-S (top panel) and PfDHS-GFP protein was detected using anti-GFP antibody (bottom panel). The migrations of PageRuler Plus Prestained Protein ladder (Thermo Scientific) standards are indicated on the left. The images are cropped for clarity. Full-length, uncropped blot images are shown in Fig. S4.

(B) Quantified Western immunoblot results. The signal intensity of the PfDHS-GFP protein band was normalized to the total protein and the PfDHS-GFP protein signal intensity in the sample lane from untreated parasites. The data from three independent experiments are shown for each parasite line. $P$-values from one-sample t-tests: 0.0082 (PfDHS_glmS, $1.25 \mathrm{mM} \mathrm{GlcN}$ ); 0.011 (PfDHS_glmS, $2.5 \mathrm{mM} \mathrm{GlcN}$ ); 0.0035 (PfDHS_glmS, $5.0 \mathrm{mM} \mathrm{GlcN}$ ); 0.15 (PfDHS_M9, $1.25 \mathrm{mM}$ GlcN); 0.45 (PfDHS_M9, $2.5 \mathrm{mM} \mathrm{GlcN}$ ) and 0.24 (PfDHS_M9, $5.0 \mathrm{mM} \mathrm{GlcN}$ ). 
A

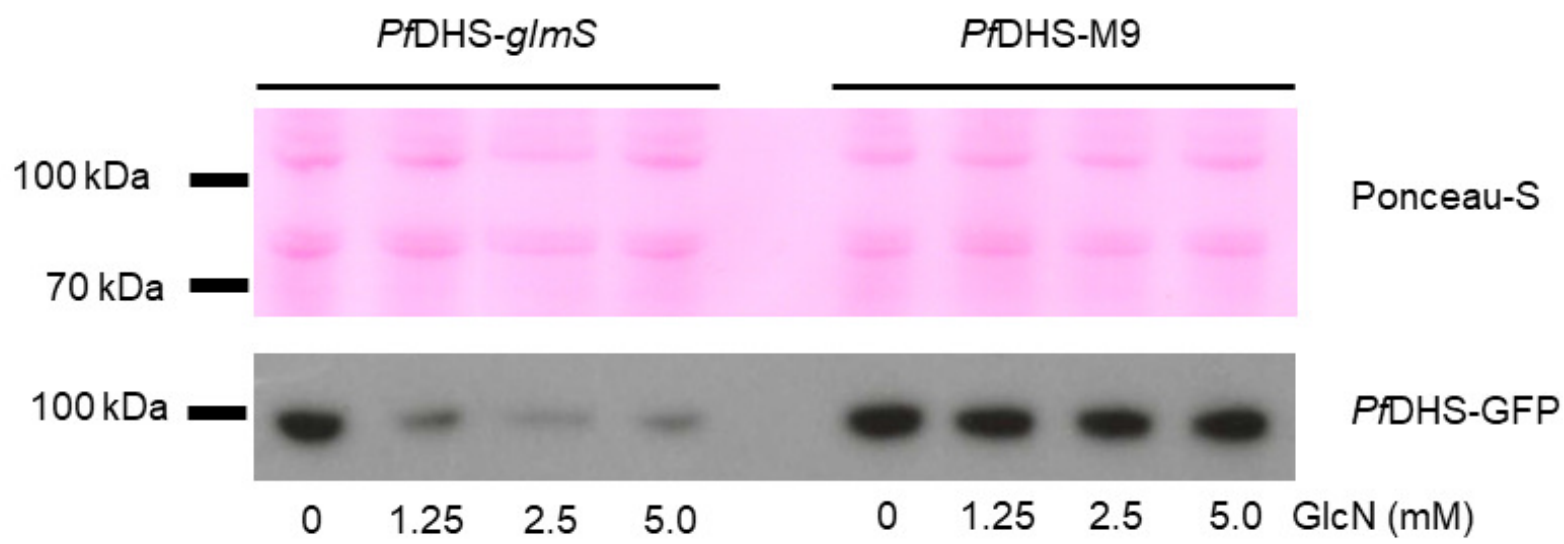

B

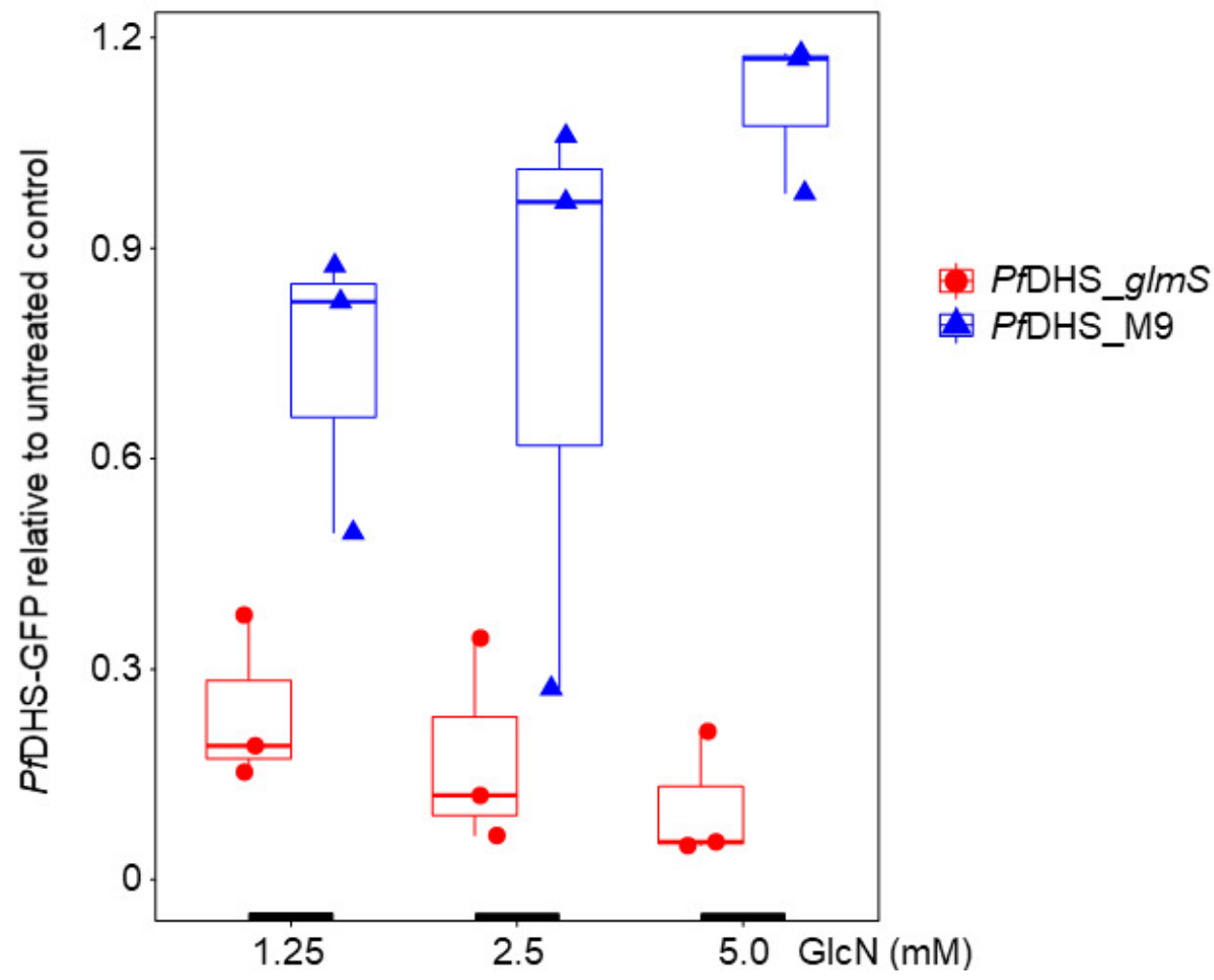




\section{Figure 3}

\section{Hypusination and nascent protein synthesis assays.}

Ring-synchronized PfDHS_gImS and PfDHS_M9 transgenic parasites were treated with $0,2.5$ or $5.0 \mathrm{mM}$ glucosamine $(\mathrm{GlcN})$ for $72 \mathrm{~h}$. For assays of nascent protein synthesis, parasites were subsequently treated with $5 \mu \mathrm{M}$ puromycin for $10 \mathrm{~min}$ prior to harvesting of parasites. Protein was extracted from parasites and separated in $4-12 \%$ NuPAGE gel. Representative data are shown in parts A-C. The images in parts A and B are cropped for clarity. Full-length, uncropped blot images are shown in Fig. S5.

(A) Total protein stained with REVERT.

(B) Hypusination assay results. A band corresponding to Plasmodium falciparum elF5A (17.6 kDa) was detected with anti-hypusine monoclonal antibody.

(C) Nascent protein synthesis assay. Puromycilated, nascent peptides were detected with anti-puromycin monoclonal antibody.

(D) Quantified hypusination assay results from seven independent experiments. $P$-values from one-sample t-tests: 7.0e-4 (PfDHS_glmS, 2.5 mM GlcN); 0.0020 (PfDHS_glmS, 5.0 mM GlcN); 0.25 (PfDHS_M9, $2.5 \mathrm{mM}$ GlcN) and 0.25 (PfDHS_M9, $5.0 \mathrm{mM} \mathrm{GlcN}$ ).

(E) Quantified puromycilation assay results from seven (PfDHS_glmS) and eight (PfDHS_M9) independent experiments. $P$-values from one-sample $t$-tests: 0.13 (PfDHS_glmS, $2.5 \mathrm{mM} \mathrm{GlcN}$ ); 0.10 (PfDHS_glmS, 5.0 $\mathrm{mM} \mathrm{GlcN}$ ); 0.58 (PfDHS_M9, $2.5 \mathrm{mM} \mathrm{GlcN}$ ) and 0.42 (PfDHS_M9, $5.0 \mathrm{mM} \mathrm{GlcN}$ ). 
A

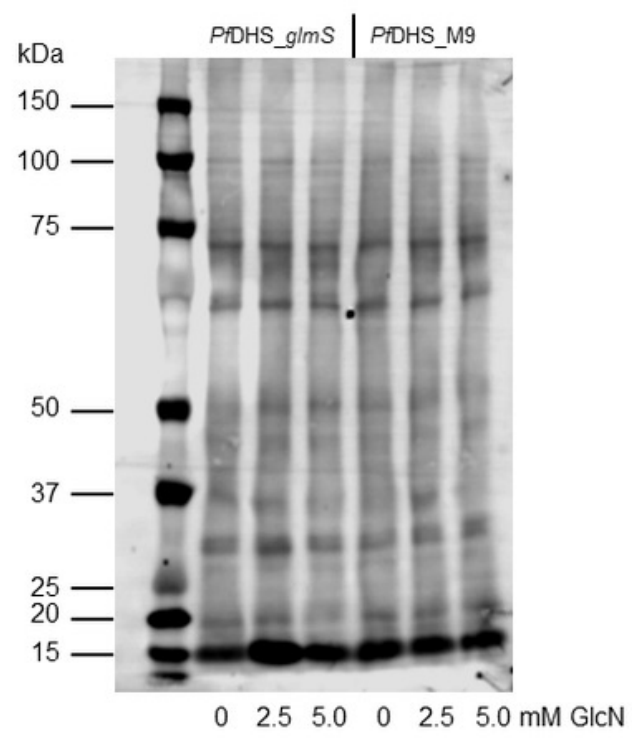

B

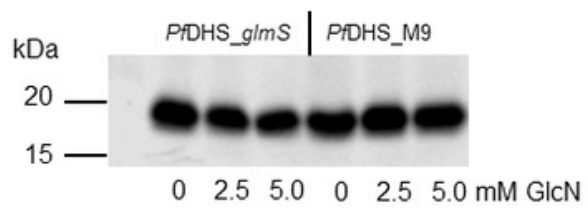

C

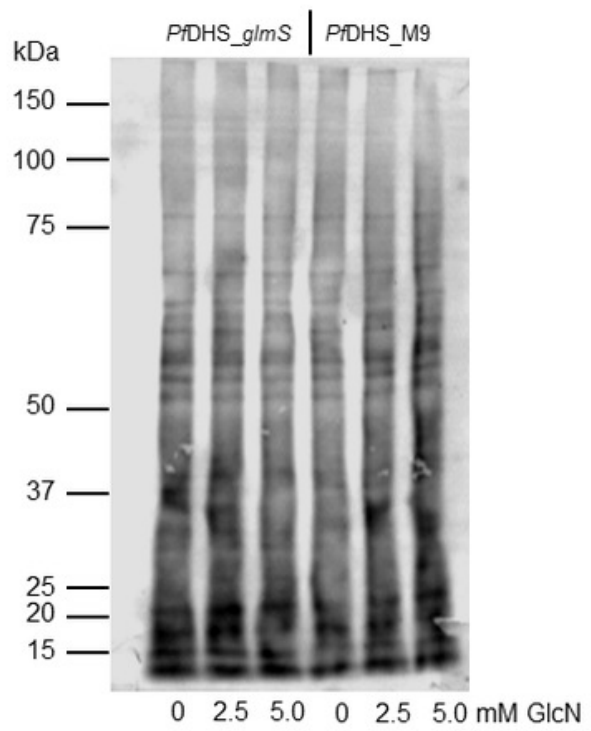

D

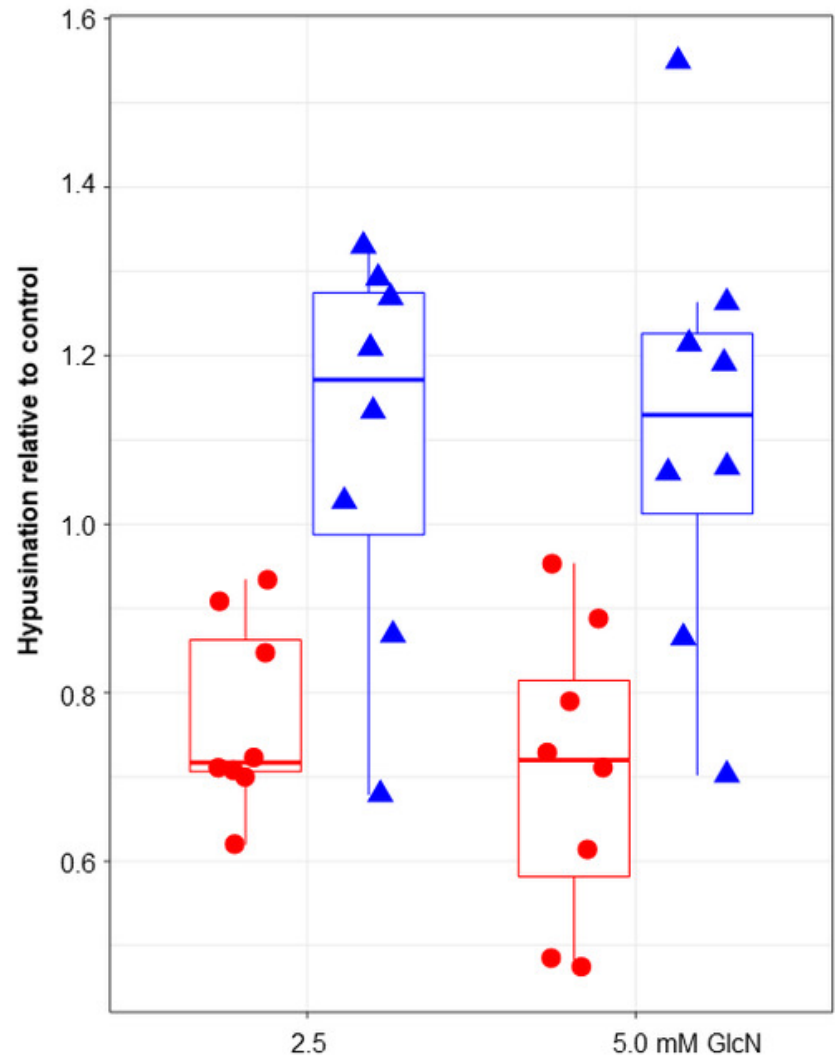

1) PfDHS_glms

PfDHS_M9

E

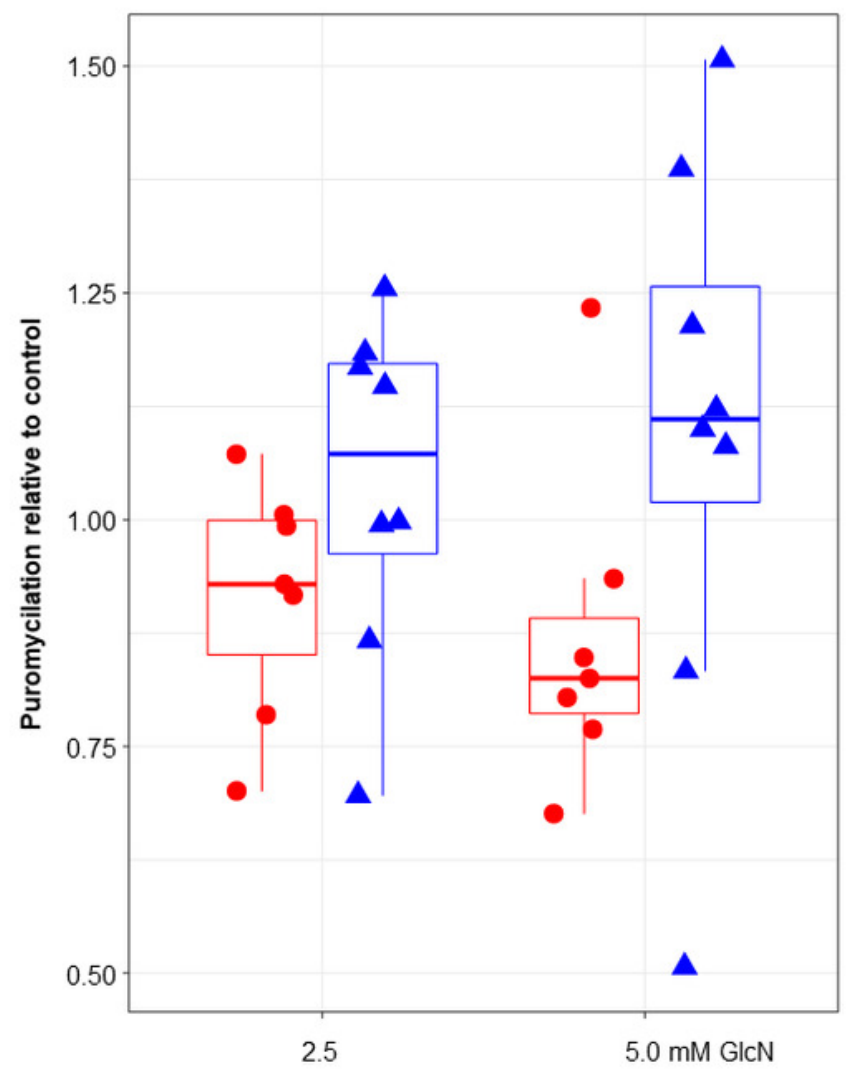

PfDHS_glmS

PfDHS_M9 


\section{Figure 4}

Growth phenotypes of transgenic parasites.

Effects of glucosamine (GlcN) on the growth of transgenic parasites in co-culture experiments are shown in parts A-C. Test transgenic parasites PfDHS_glmS (A), PfDHS_M9 (B) and PfDHFR-TS_gImS (C) were combined with control PfFC_gImS parasites in a 1:1 ratio and cocultured. Samples were taken from the culture every two growth cycles until the tenth cycle. The ratio of test:control transgenic parasite at each time-point was determined by qPCR using primers specific for each transgenic parasite. This ratio was taken as the relative growth value for modelling. The data from three independent experiments for each condition are shown. The lines on the graphs are the linear mixed effect models of growth at the indicated treatment doses of GIcN. P-values from likelihood ratio test: 0.0024 (PfDHS_glmS); 0.19 (PfDHS_M9); 3.9e-11 (PfDHFR-TS_gImS). Part D shows the effect of GICN on modulating transgenic parasite sensitivity to growth inhibitory compounds. Dose-response assays were performed with (2.5 mM) or without GlcN co-treatment. Three or four independent experiments were performed for each condition. The growth inhibitory compounds tested included cycloheximide (CHX), $N^{1}$-guanyl-1,7-diaminoheptane (GC7) and pyrimethamine (PYR). The $50 \%$ inhibitory concentration of each compound $\left(\mathrm{EC}_{50}\right)$ was determined by analysis of dose-response data for PfDHS_glmS and PfDHS_M9 transgenic parasites. The doseresponse data and fitted curves are shown in Fig. S11. The estimated $\log _{2}$ ratio of $\mathrm{EC}_{50}$ between the $-\mathrm{GlcN}$ and $+\mathrm{GlcN}$ conditions together with $\mathrm{Cl}_{95}$ is shown for each compound and transgenic parasite. $P$-values comparing $\log _{2} \mathrm{EC}_{50}(-\mathrm{GlcN} /+\mathrm{GlcN})$ estimates: 0.76 (PfDHS_glmS, CHX); 2.0e-15 (PfDHS_glmS, GC7); 0.030 (PfDHS_glmS, PYR); 0.28 (PfDHS_M9, CHX); 0.0031 (PFDHS_M9, GC7); 9.0e-4 (PFDHS_M9, PYR). 
A

PfDHS_glmS relative growth

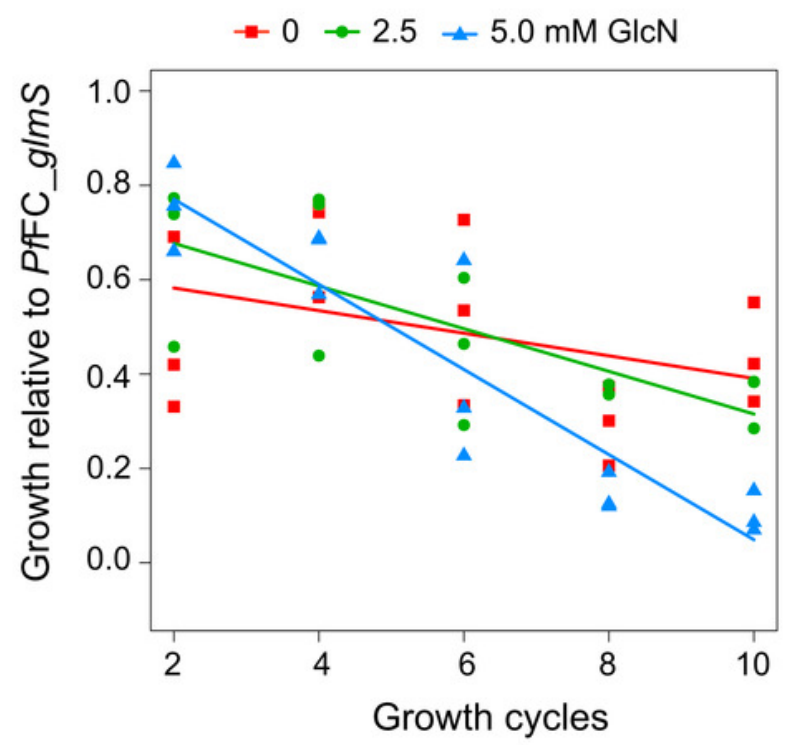

C

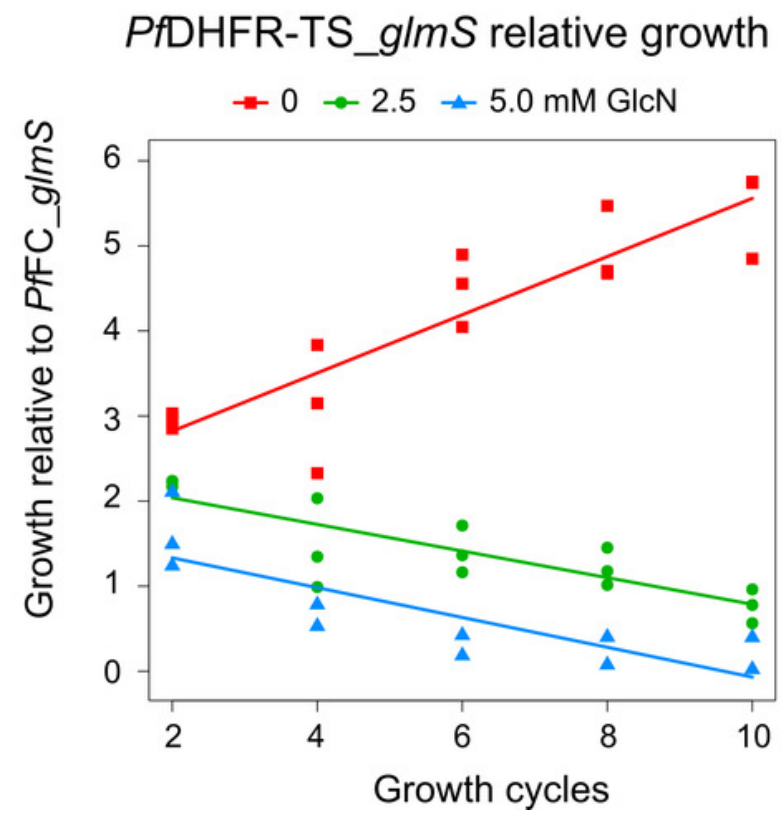

B PfDHS_M9 relative growth

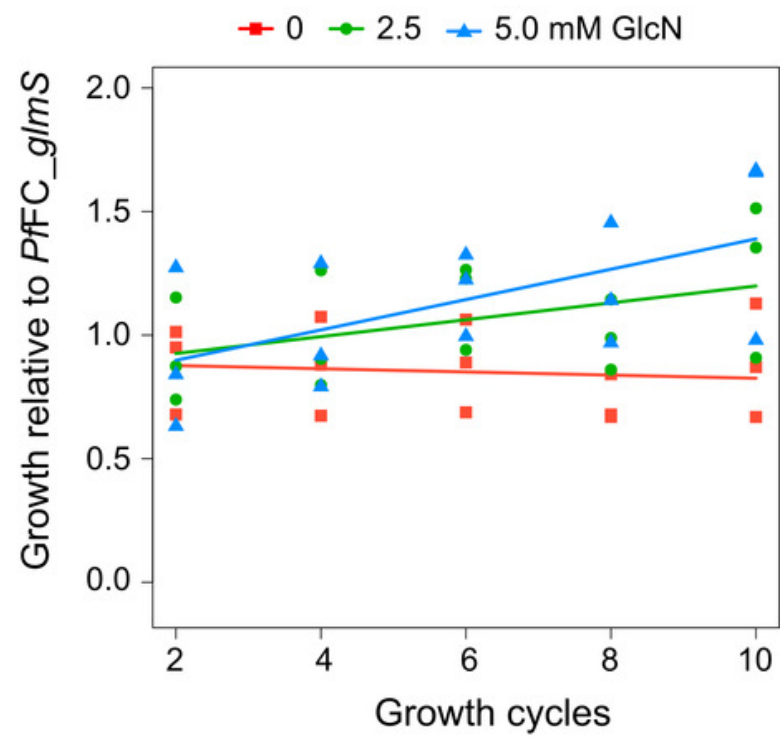

D

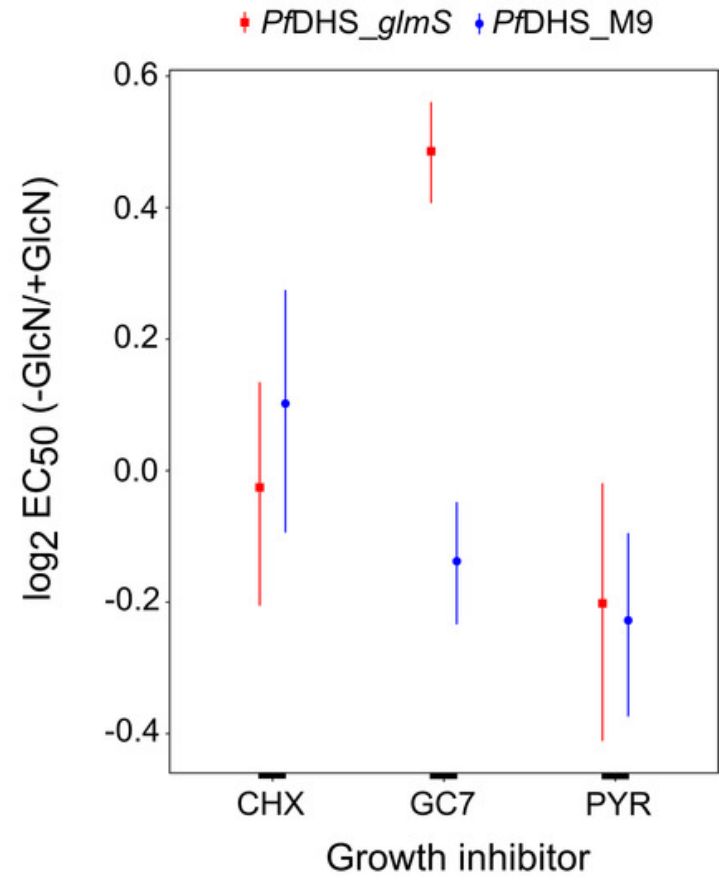


Figure 5

Homology model of PfDHS structure.

The modeled PfDHS structure is a tetramer of subunits. The subunit cores are colored in magenta, yellow, cyan and green. PfDHS insertion loops with no homologous residues in human DHS are colored in orange. The alignment of PfDHS with human DHS template (PDB: 1RLZ) is shown in Fig. S12.

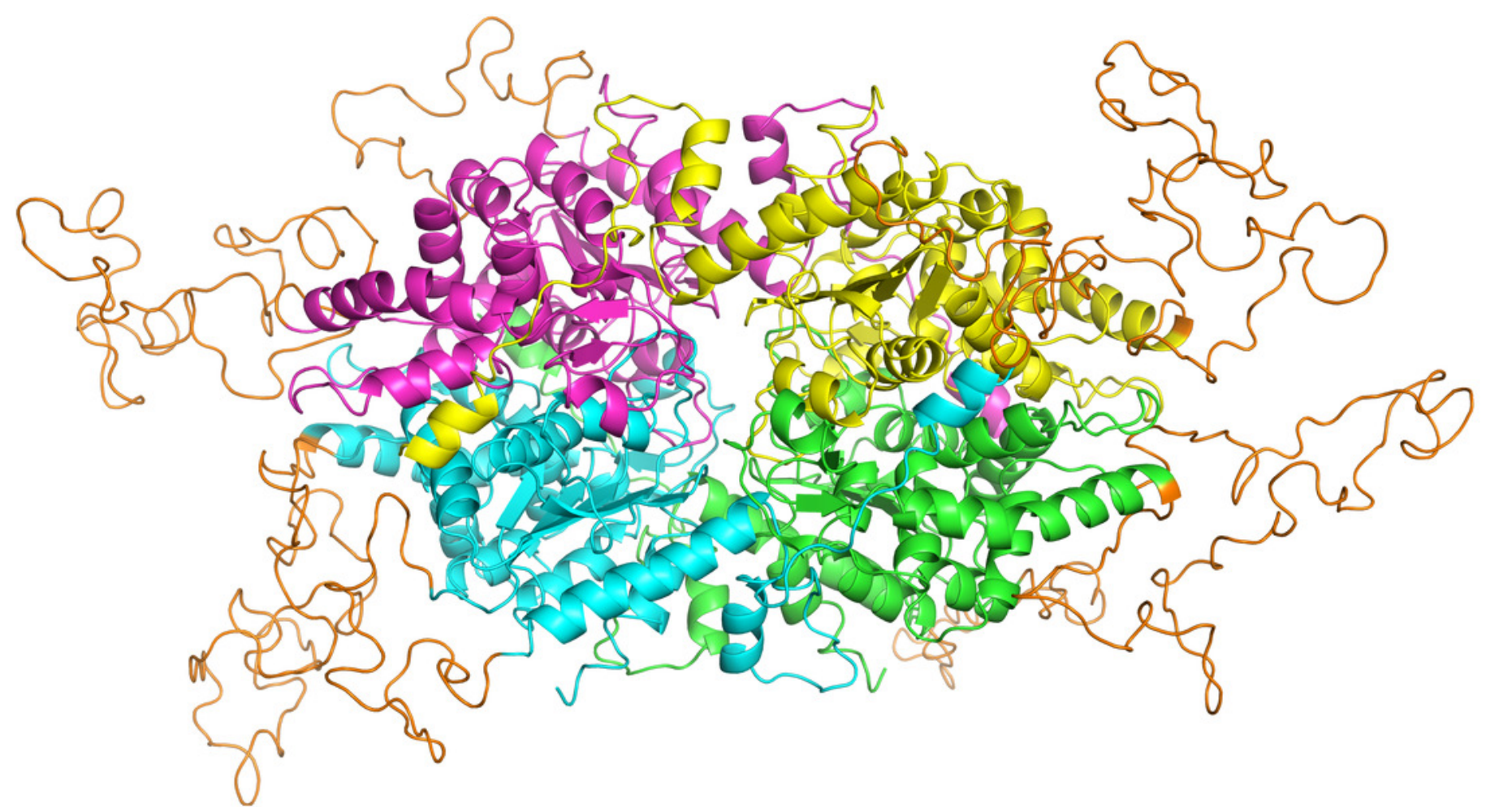




\section{Figure 6}

\section{PfDHS putative substrate binding pocket and GC7 interaction.}

(A) PfDHS homology model with the top scoring ligand binding site identified by SiteMap in orange. PfDHS tetramer subunits are colored in magenta, yellow, cyan and green. An alternative view of the same structure rotated 90 degrees is shown on the right.

(B) Superposition of the human DHS (PDB: 1RQD) substrate binding pocket (gray) with PfDHS top scoring ligand binding site identified by SiteMap (orange). The NAD and GC7 molecules co-complexed with human DHS are shown for one subunit.

(C) Superposition of the human DHS (PDB: 1RQD) GC7 binding domain (green) and corresponding region in PfDHS (purple). Key conserved DHS residues interacting with GC7 are shown, with numbering of human DHS residues followed by the PfDHS counterpart.

(D) Interaction map of human DHS residues in the GC7 binding domain. Residues are numbered according to which subunit (A-D) they belong to. Interactions between residues and GC7 are shown by arrows. Red arrow depicts p-cation, blue arrows salt-bridge and magenta arrows hydrogen bond interactions. Interaction map of PfDHS residues in the GC7 binding domain. Residues are numbered according to which subunit (A-D) they belong to. Interactions between residues and GC7 are shown by arrows. Red arrow depicts $\pi$-cation, blue arrows salt-bridge and magenta arrows hydrogen bond interactions. 
A

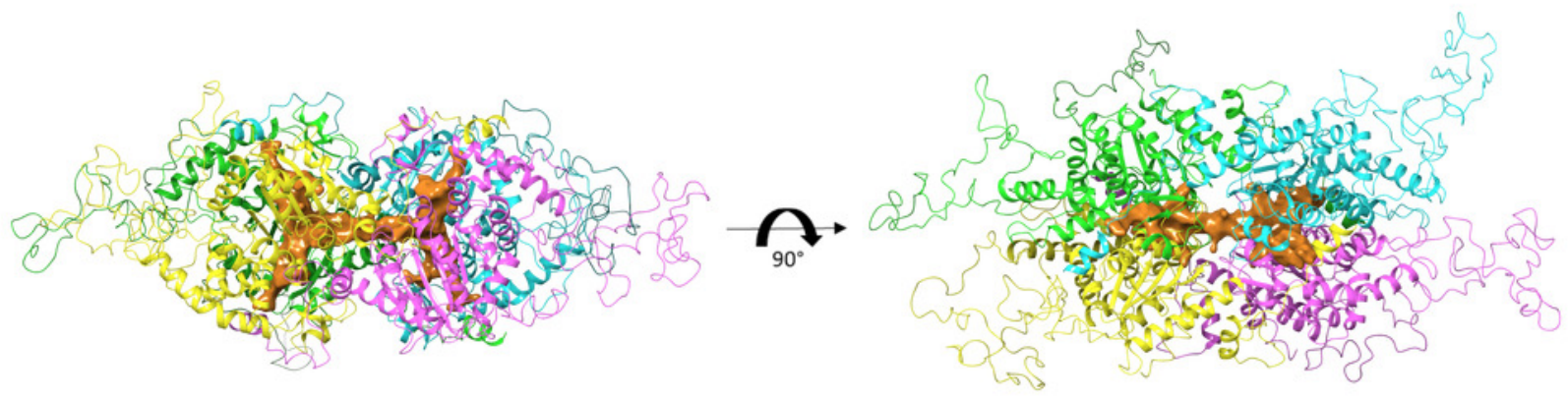

B

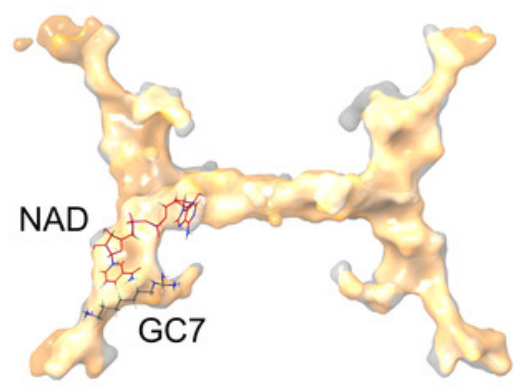

D

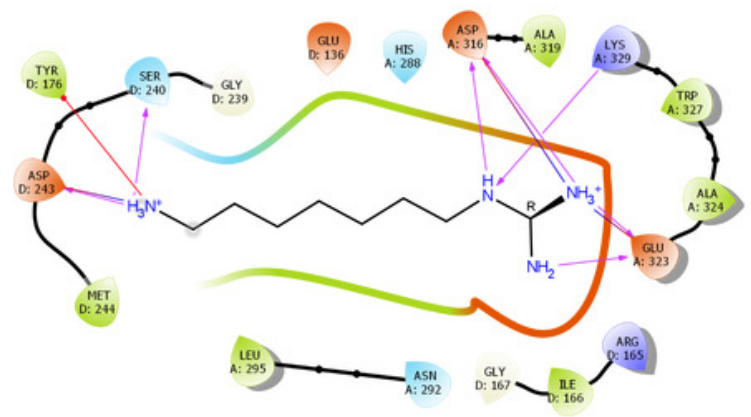

C

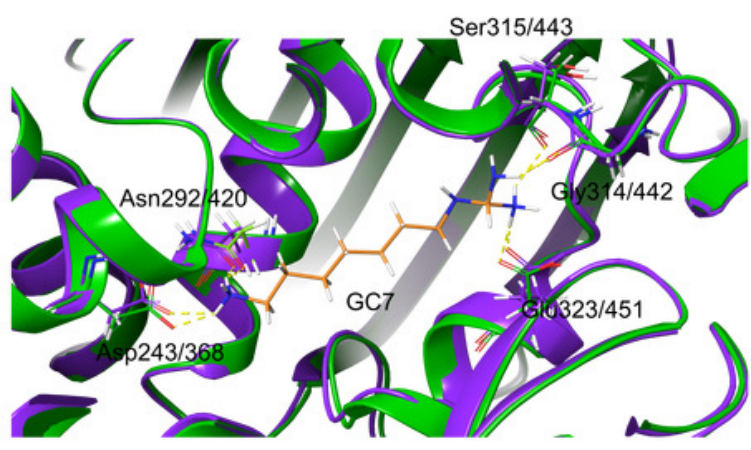

$\mathbf{E}$

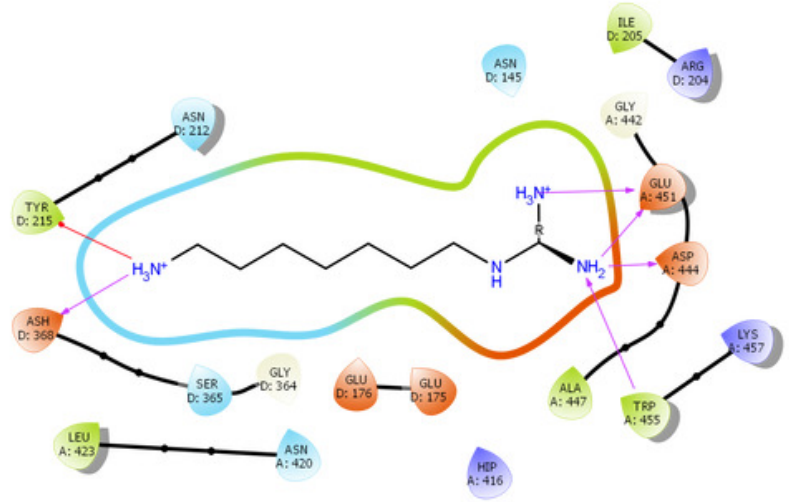

